\title{
CREDIT HORIZONS
}

\author{
Nobuhiro Kiyotaki \\ John Moore \\ Shengxing Zhang \\ Working Paper 28742 \\ http://www.nber.org/papers/w28742
}

\author{
NATIONAL BUREAU OF ECONOMIC RESEARCH \\ 1050 Massachusetts Avenue \\ Cambridge, MA 02138 \\ April 2021
}

We would like to thank the U.S. National Science Foundation and the U.K. Economic and Social Research Council for financial support. The views expressed herein are those of the authors and do not necessarily reflect the views of the National Bureau of Economic Research.

NBER working papers are circulated for discussion and comment purposes. They have not been peer-reviewed or been subject to the review by the NBER Board of Directors that accompanies official NBER publications.

(C) 2021 by Nobuhiro Kiyotaki, John Moore, and Shengxing Zhang. All rights reserved. Short sections of text, not to exceed two paragraphs, may be quoted without explicit permission provided that full credit, including $(\odot$ notice, is given to the source. 
Credit Horizons

Nobuhiro Kiyotaki, John Moore, and Shengxing Zhang

NBER Working Paper No. 28742

April 2021

JEL No. E44

\begin{abstract}
$\underline{\text { ABSTRACT }}$
Entrepreneurs appear to borrow largely against their near-term revenues, even when their investment has a longer horizon. In this paper, we develop a model of credit horizons. A question of particular concern to us is whether persistently low interest rates can stifle economic activity. With this in mind, our model is of a small open economy where the world interest rate is taken to be exogenous. We show that a permanent fall in the interest rate can reduce aggregate investment and growth, and even lead to a drop in the welfare of everyone in the domestic economy. We use our framework to examine how credit horizons interact with plant dynamics and the evolution of productivity. Finally, we speculate that the measurement of total investment may camouflage the true level of productive investment in plant and human capital, and give too rosy a picture of property-fuelled booms sparked by low interest rates.
\end{abstract}

Nobuhiro Kiyotaki

Department of Economics

Princeton University

Fisher Hall

Princeton, NJ 08544-1021

and NBER

kiyotaki@princeton.edu

John Moore

William Robertson Building

Edinburgh

Scotland, EH8 9JY

U.K.

j.h.moore@ed.ac.uk
Shengxing Zhang

Department of Economics

London School of Economics

and CEPR

oo7zsx@gmail.com 


\section{Introduction}

When financing long-term capital investment, entrepreneurs typically borrow against their future cash flow and put up their fixed assets as collateral. ${ }^{1}$ The amount borrowed may be only a few years' worth of revenue. ${ }^{2}$ Entrepreneurs appear to borrow largely against their near-term revenues, even when their investment has a longer horizon.

In this paper, we develop a model of credit horizons. A question of particular concern to us is whether persistently low real interest rates can stifle aggregate investment and growth. The question is motivated by Japan, where the economy struggles to regain robust growth despite interest rates having been close to zero for over two decades. Recently, this has become a concern for other developed economies too. With this in mind, we model a small open economy where the world interest rate, $R$, is taken to be exogenous.

To get a flavour of our model, think of an engineer-cum-entrepreneur, Emma, raising funds to invest in plant within a building. For our purposes, it does not matter whether the building is leased long-term or purchased outright. The critical thing is that there will be an ongoing flow of fixed costs that will have to be paid to maintain production in the long run either rent on the building or the opportunity cost of owning the building. There is no obstacle to Emma raising funds against the plant: this can be sold at the time of investment. What cannot be sold is Emma's engineering expertise, her human capital, which is acquired through learning by doing associated with her gross investment. This inalienability constrains Emma's ability to borrow, so the scale of her investment is limited by her net worth. ${ }^{3}$

A saver, Sam, who buys the plant, together with an obligation to pay the flow of fixed costs, will subsequently need engineers' expertise to maintain the productivity. Without adequate maintenance by engineers, the productivity of his plant would slowly deteriorate. We adopt a form of 'roundabout' tech-

\footnotetext{
${ }^{1}$ Lian and Ma (2021) examine firm-level data of US non-financial corporations to document that approximately $80 \%$ of corporate borrowing is backed by future cash flow and only $20 \%$ by collateral assets - though this $4: 1$ ratio tends to be lower for smaller US firms and lower in other countries like Japan. Drechsel (2020) also documents that much of US corporate borrowing is constrained by firms' current earnings.

${ }^{2}$ Lian and Ma (2021) further examine debt covenants to find that, at the 25 percentile, the cash-flow-based debt is restricted by 3 years' worth of EBITDA (earnings before interest, taxes, depreciation and amortization) and, at the 75 percentile, by 4.5 years' worth.

${ }^{3}$ Hart and Moore (1994).
} 
nology, inspired by Böhm-Bawerk (1889): we suppose that tomorrow's plant productivity is a function of both today's productivity and today's engineering input. Hence, although the present productivity is historically given, the long-run future productivity will mostly depend upon the cumulative effort of engineers.

We abstract from specificity of match between plant and engineers: we allow for an ex post competitive market in which plant owners hire the maintenance services of engineers. Thus Emma's share of ex post surplus is determined through competition - she may work for Sam or some other plant owner. Each day, Sam employs Emma or another engineer, paying her forward-looking marginal product, her contribution to future productivity. ${ }^{4}$

Crucially, because her human capital is inalienable, Emma cannot commit to Sam ex ante to supply her maintenance services for less than the ex post market rate. (If she could, Sam would be willing to pay her more for the plant and she would in effect be able to borrow more and thus invest more.) This form of constraint - our sole departure from the Arrow-Debreu model - is sometimes called a non-exclusivity constraint. ${ }^{5}$

A primary concern for Emma is: How much funding can she raise from savers like Sam at the time of investment? That is, her borrowing capacity is the amount Sam is willing pay per unit of new plant, which in turn depends on Sam's assessment of his share of the future surplus from that plant, net of the fixed costs. The scale of Emma's investment will be given by a critical ratio, familiar from many models of investment under financing constraints: namely, her net worth divided by the required downpayment, where that downpayment equals her unit investment cost minus her borrowing capacity.

The key insight is that the fraction of plant productivity attributable to engineers' cumulative maintenance rises with the age of plant, given that engineers cannot precommit to work for less than their forward-looking marginal product. Concomitant with the engineers' share rising, Sam's share of gross return from the plant falls through time. Hence the price of new plant - Emma's borrowing capacity - is largely governed by revenues in the near horizon. ${ }^{6}$

\footnotetext{
${ }^{4}$ If we assumed there were match specificity - if Sam were to need Emma's particular expertise to maintain the plant - then they might engage in bilateral bargaining ex post. We believe our findings would be broadly similar under this alternative assumption.

${ }^{5}$ See, for example, Allen (1985), Townsend (1989), Cole and Kocherlakota (2001) and Attar, Mariotti and Salanie (2011).

${ }^{6} \mathrm{De}$ la $\mathrm{O}$ and Myers (2021) find that expectations of cash flow growth in the near future
} 
What happens if the real interest rate $R$ falls permanently? For Sam, there is a duration gap: his share of gross revenue is predominantly near term, while his obligation to pay the fixed costs of the building is long term. When $R$ is lower, because the present value of his long-term obligations increases proportionately more than that of his near-term revenue share, Sam's willingness to pay for new plant can be lower. This means that Emma's borrowing capacity is lower - overturning the usual notion that lower interest rates benefit borrowers.

Notice the driver here: per unit of investment, the required downpayment (investment cost minus borrowing capacity) - the denominator in the critical ratio of net worth divided by downpayment - rises as $R$ falls, owing to the fall in borrowing capacity. In the macro-finance literature, the focus has been on how the numerator - the net worth of credit-constrained agents - might move in curious ways following shocks to an economy. In the present model, the numerator behaves as might be expected - a fall in $R$ raises net worth - but this can be more than offset by the rise in the denominator. Overall, domestic investment can fall with a fall in world interest rates, as can the growth rate. We demonstrate numerically that these effects may reduce the welfare of everyone in the domestic economy: a fall in $R$ may lead to a Pareto deterioration.

In terms of policy intervention, we show there can be scope for an investment subsidy, financed by a plant-level payroll tax on engineers' maintenance services. This policy can improve welfare by implementing a form of additional group borrowing by the engineers, although the success of any such policy depends on exactly what the government is able to monitor.

Measurement of total investment in the economy may include the cost of buildings. Think of Emma, at the time of investment, outlaying not only the cost of plant and human capital but also the cost of the building in which the plant is located. She partly funds these costs by selling both the plant and the building to Sam. Now a fall in $R$, that pushes up the cost of buildings, may boost measured total investment and so appear in a positive light. But this camouflages the fact that investment in the engine of growth, the plant and human capital, has fallen, because Emma's total borrowing capacity, the amount Sam pays her for the plant plus building, hasn't risen as much as her total investment costs. We find that, following an unexpected persistent fall in the interest rate, measured total investment (including buildings) initially

explain most movements in the S\&P 500 price-dividend and price-earnings ratios. 
increases before tailing off to grow at a stagnated rate. We speculate that the disparity between measured total investment (which rises) and investment in plant and human capital (which falls) may have given too rosy a picture of a number of property-fuelled booms sparked by lower interest rates, such as the Japanese property boom in the late 1980s, or the property boom in southern Europe following the introduction of the euro in the early 2000s.

Before laying out details of our model, we should highlight the subtle firm dynamics - more specifically, plant dynamics - that can emerge. As the owner of new plant, Sam has to decide on a maintenance plan. It turns out he has a distinct choice. Either he curbs maintenance costs and allows productivity to deteriorate slowly, to some point when he decides it is no longer worth paying the fixed costs and exits - call this his "stopping strategy". Or he pays the costs needed to maintain, or even improve, productivity with a view to staying in production over the long haul - call this his "continuing strategy".

This dichotomous decision - either planning to stop within a finite horizon, or planning to continue for the long haul - reveals an intriguing feature of equilibrium. For an open set of parameters, even though all plant starts off identical in productivity, their qualities diverge over time: some plant improves in productivity and other plant deteriorates and eventually shuts down. ${ }^{7}$ We think this may be a rich new vein for research into firm/plant dynamics, which should inform the study of how aggregate productivity evolves.

\section{Model}

We consider a small open economy with an exogenous world real interest rate $R$. There is no aggregate uncertainty and, for the moment, we focus on steady state equilibrium (later, we will examine the effects of an unanticipated persistent drop in $R$ ). There is a homogeneous perishable consumption/investment good at each date $t=0,1,2, \ldots$ We use this good as numeraire as we consider a non-monetary economy.

There is a continuum of domestic agents, each maximizing utility of con-

\footnotetext{
${ }^{7}$ Allowing for initial heterogeneity would purify (Aumann et al. (1983)) this mixedstrategy equilibrium so that plant owners would, more realistically, follow pure strategies.

In the complementary part of the parameter space, all owners of new plant choose the continuing strategy and their qualities do not diverge.
} 
sumption $c_{t}$ from the present to the infinite future:

$$
E_{0}\left[\sum_{t=0}^{\infty} \beta^{t} \ln c_{t}\right]
$$

where $\beta \in(0,1)$ is the utility discount factor and $\ln c$ is the natural logarithm of $c$. We assume that the exogenous world interest rate is nonnegative in net terms and lower than the subjective interest rate:

$$
1 \leq R<\frac{1}{\beta}
$$

Each agent sometimes has an investment opportunity (being an entrepreneur or simply "engineer"), and sometimes not ("saver"). The transition probabilities of being an engineer conditional on being an engineer or a saver in the previous period are given by

$$
\begin{aligned}
\text { Prob (engineer at } t \mid \text { engineer at } t-1) & =\pi^{E}, \\
\text { Prob (engineer at } t \mid \text { saver at } t-1) & =\pi^{S} .
\end{aligned}
$$

We assume the arrival of an investment opportunity is persistent to a limited degree so that $0 \leq \pi^{S} \leq \pi^{E}<1$.

At each date $t$, an engineer can jointly produce plant and tools from goods: within the period, per unit of plant,

$$
x \text { goods } \rightarrow\left\{\begin{array}{c}
\text { plant of productivity } 1 \\
\text { E-tool }
\end{array} .\right.
$$

The investment technology is constant returns to scale and scalable by any positive number $i$. Plant and tools are ready for use from date $t+1$. Here we can think of tools as the engineer's human capital acquired through her learning by doing. As in Arrow (1962), the learning by doing is associated with gross investment instead of regular production.

Each tool (or human capital) is specific to the engineer ("E-tool") in that only she knows how to use it - unless she sells it to another engineer and teaches him. Because the engineer cannot usefully sell her tools to savers and her human capital is inalienable, she raises funds by selling all that she can, the plant.

The plant owner has a constant returns to scale production technology. At each date, the owner of one unit of plant of productivity $z$ can hire any 
number $h \geq 0$ of tools (hiring each tool along with the engineer who knows how to use it) at a competitive rental price $w$ ("wage") to produce goods and maintain plant productivity: within the period, per unit of plant,

$$
\left.\begin{array}{c}
\text { plant of productivity } z \\
h \text { tools } \\
f \text { goods }
\end{array}\right\} \rightarrow\left\{\begin{array}{c}
y=a z \text { goods } \\
\lambda \text { plant of productivity } z^{\prime}=z^{\theta} h^{\eta} . \\
\lambda h \text { tools }
\end{array}\right.
$$

$a>0$ is the common productivity of all plant and $z^{\prime}$ is plant productivity after maintenance. $f$ is a fixed cost per unit of plant, and $\lambda<1$ reflects depreciation, by which a fraction $1-\lambda$ of plant and tools are destroyed after use. The fixed cost can be thought of as the rental price or the opportunity cost of owning the building in which plant is located. The parameter $\theta$ is the share of initial plant productivity and $\eta$ is the share of engineers' tools in maintaining plant productivity. We assume that $\theta, \eta>0$, and $\theta+\eta \leq 1$.

A brief word about interpretation is in order here. Although we call $w$ the engineer's "wage", it is important to distinguish it from the simple wage of, say, an unskilled worker. The engineer's remuneration is like payment to a skilled core employee who influences the firm's future productivity. ${ }^{8}$ Notice that, unlike in a more fleshed-out macroeconomic framework, we assume a simple reduced-form production of output: proportional to the productivity of the plant. In Appendix A we show that this formulation is justified when output is a general decreasing returns to scale function of plant productivity and unskilled labor, where unskilled labor is hired by plant owners in a competitive market.

The plant owner always has the option to stop, so his value of a unit of plant of productivity $z$ at the end of the period is given by

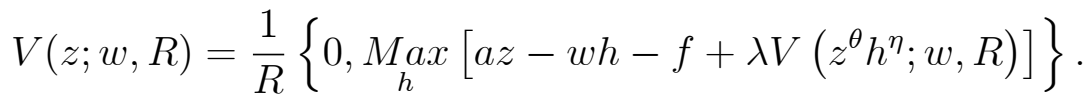

The zero inside the braces is the value of stopping, while the second term is the value of continuing - the sum of net cash flow (gross revenue minus wage and fixed costs) and the capital value of the remaining $\lambda$ units of plant with productivity $z^{\prime}=z^{\theta} h^{\eta}$.

Knowing that the return from maintaining plant productivity depends upon his future production and maintenance choices, the plant owner must

\footnotetext{
${ }^{8}$ Whether the remuneration is a spot payment or a claim to future revenue of the plant does not matter, because, to finance downpayment, an investing engineer can equally use a spot payment or the sale of a claim.
} 
devise a long-term plan: Either stop after a finite number of periods $T$, or continue forever $(T=\infty)$ ? For each $T=0,1,2, \ldots$, define recursively the owner's value of a unit of plant of current productivity $z$ stopping in $T$ periods:

$$
\begin{aligned}
S^{0}(z ; w, R) & =0 \\
S^{1}(z ; w, R)= & \frac{1}{R}(a z-f), \\
S^{2}(z ; w, R)= & \frac{1}{R} M_{h} a x\left[a z-w h-f+\frac{\lambda}{R}\left(a z^{\theta} h^{\eta}-f\right)\right], \\
S^{T}(z ; w, R)= & \frac{1}{R} M_{h} a x\left[a z-w h-f+\lambda S^{T-1}\left(z^{\theta} h^{\eta} ; w, R\right)\right] .
\end{aligned}
$$

If the plant is shut down tonight, the value $S^{0}(z ; w, R)$ is zero. If the plant owner shuts down tomorrow night, he will not hire tools tomorrow and the value $S^{1}(z ; w, R)$ equals the present value of tomorrow's revenue minus fixed cost. If the plant owner shuts down in two nights' time, he hires tomorrow's tools to balance the cost and benefit of maintaining plant productivity for production two days later. Generally, the owner's value of a unit of plant of current productivity $z$ stopping in $T$ periods, $S^{T}(z ; w, R)$, equals the present value of the sum of tomorrow's net cash flow and the value of $\lambda$ units of plant of productivity $z^{\theta} h^{\eta}$ stopping in $T-1$ periods.

Now, for all value of $z$, the plant owner chooses the optimal stopping time so that

$$
V(z ; w, R) \equiv \sup _{T \geq 0} S^{T}(z ; w, R) .
$$

Because new plant that she sells to a saver at the time of investment has productivity 1 , the engineer raises, per unit of plant,

$$
b=V(1 ; w, R) .
$$

The value $b$ can be thought of as the engineer's borrowing capacity per unit of investment.

The required own-funds (downpayment) per unit of investment equals the gap between the investment cost and the borrowing capacity:

$$
x-b .
$$

We assume that a new saver - an engineer yesterday who switched to being a saver today - can sell her tools (after use today) to an engineer, and teach him how to use them, at a competitive price $x-b$. 
The budget constraint of an agent at date $t$ who has $h_{t}$ tools and $d_{t}$ financial assets is

$$
c_{t}+(x-b) i_{t}+\frac{d_{t+1}}{R}=w h_{t}+d_{t},
$$

where $h_{t}$ is positive only if the agent was an engineer yesterday. Here, financial assets consist of the value of plant ownership as well as maturing one-period discount bonds. The discount bond is traded internationally at the interest rate $R$. Only if the agent is an engineer today, investment $i_{t}$ can be positive and her tools tomorrow will be

$$
h_{t+1}=\lambda h_{t}+i_{t} .
$$

The budget constraint can be rewritten as

$$
c_{t}+(x-b) h_{t+1}+\frac{d_{t+1}}{R}=[w+\lambda(x-b)] h_{t}+d_{t}=n_{t},
$$

where $n_{t}$ is net worth - the sum of flow return (wage) and capital value (replacement cost or resale value) of tools, plus financial assets.

The rate of return for an engineer investing with maximal borrowing is given by

$$
R^{E}=\frac{w+\lambda(x-b)}{x-b},
$$

the ratio of total returns of one tool to the downpayment of investment. (Remember she sells plant to a saver at the time of investment and so does not receive the return on plant.) If the return on investment $R^{E}$ exceeds the interest rate $R$, then, thanks to the logarithmic utility function, the engineer's consumption and investment are

$$
\begin{aligned}
c_{t} & =(1-\beta) n_{t}, \\
(x-b) h_{t+1} & =\beta n_{t} .
\end{aligned}
$$

And a saver's consumption and asset holdings are

$$
\begin{aligned}
c_{t} & =(1-\beta) n_{t}, \\
\frac{d_{t+1}}{R} & =\beta n_{t} .
\end{aligned}
$$

Notice that individual consumption depends only on present net worth and not on whether the agent has an investment opportunity today. Because 
marginal utility is independent of whether or not there is an investment opportunity, there are no gains from insurance (such as the agent receives a bonus if she has an investment opportunity while pays a premium if not).

A steady state equilibrium of our small open economy is characterized by the wage $w$ and the new plant price $b$, together with the quantity choices of savers/plant owners $(c, d, h, z, y)$, engineers $(c, h, i)$, and foreigners (who have net asset holdings $D^{*}$ ), such that the markets for goods, tools, plant, and bonds all clear.

\section{Pure Equilibrium with No Stopping}

We use a guess and verify method to characterize equilibrium. Suppose that in the steady state, no plant owner shuts down his plant until it depreciates exogenously. Then the value function (5) is the present value of net cash flow into the indefinite future:

$$
\begin{aligned}
& V(z ; w, R) \\
= & \frac{1}{R}\left(y_{t}-w h_{t}-f\right)+\frac{\lambda}{R^{2}}\left(y_{t+1}-w h_{t+1}-f\right)+\frac{\lambda^{2}}{R^{3}}\left(y_{t+2}-w h_{t+2}-f\right) \\
& +\ldots
\end{aligned}
$$

An optimal sequence $\left\{h_{t}, z_{t+1}, h_{t+1}, z_{t+2}, h_{t+2}, \ldots\right\}$ equates the discounted sum of marginal product to the wage (see Appendix B for the derivation):

$$
\begin{aligned}
w= & \frac{\lambda}{R} a \eta \frac{z_{t+1}}{h_{t}}+\left(\frac{\lambda}{R}\right)^{2} a \eta \frac{z_{t+1}}{h_{t}} \theta \frac{z_{t+2}}{z_{t+1}}+\left(\frac{\lambda}{R}\right)^{3} a \eta \frac{z_{t+1}}{h_{t}} \theta \frac{z_{t+2}}{z_{t+1}} \theta \frac{z_{t+3}}{z_{t+2}} \\
& +\ldots
\end{aligned}
$$

The first term on the right hand side is the marginal impact of a date-t tool on output $y_{t+1}$ through its impact on plant productivity $z_{t+1}$. The second term is the marginal impact of the date-t tool on $y_{t+2}$ through its impact on $z_{t+1}$ which impacts $z_{t+2}$. The third term is the marginal impact of the date-t tool on $y_{t+3}$ through its impact on $z_{t+1}$ which impacts $z_{t+2}$ which in turn impacts $z_{t+3}$.

Multiplying through by $h_{t}$ and simplifying, we get

$$
w h_{t}=\frac{\lambda}{R} \eta y_{t+1}+\frac{\lambda^{2}}{R^{2}} \eta \theta y_{t+2}+\frac{\lambda^{3}}{R^{3}} \eta \theta^{2} y_{t+3}+\ldots
$$


The present wage bill for engineers equals the present discounted value of a fraction $\eta$ of tomorrow's output, plus a fraction $\eta \theta$ of output two periods later, plus a fraction $\eta \theta^{2}$ of output three periods later, etc.

An engineer raises funds by selling new plant at price

$$
\begin{aligned}
b= & V(1 ; w, R) \\
= & \frac{1}{R}(a-f)+\frac{\lambda}{R^{2}}\left[y_{t+1}(1-\eta)-f\right]+\frac{\lambda^{2}}{R^{3}}\left[y_{t+2}(1-\eta-\eta \theta)-f\right] \\
& +\ldots
\end{aligned}
$$

All plant starts with productivity $z=1$. Moreover, investment generates an equal number of plant and tools, which have the same technological depreciation rate $1-\lambda$. If no plant is stopped, the ratio of tools to plant stays one-to-one. Then because

$$
z^{\prime}=z^{\theta} h^{\eta}=1 \text { when } z=h=1,
$$

all plant is maintained at initial productivity $z=1$ until the exogenous death of plant through depreciation. Output per unit of plant is unchanged from the initial level:

$$
y_{t+1}=y_{t+2}=y_{t+3}=\ldots=a .
$$

The engineer's borrowing capacity $b$ becomes

$$
b=\frac{1}{R}(a-f)+\frac{\lambda}{R^{2}}[a(1-\eta)-f]+\frac{\lambda^{2}}{R^{3}}[a(1-\eta-\eta \theta)-f]+\ldots
$$

Notice how the plant owner's share of gross output declines over time: 1, $1-\eta, 1-\eta-\eta \theta, \ldots$ By calculating the present value of the engineers' payoff from new plant

$$
\begin{aligned}
& \frac{1}{R} w+\frac{\lambda}{R^{2}} w+\frac{\lambda^{2}}{R^{3}} w+\ldots \\
= & 0+\frac{\lambda}{R^{2}} a \eta+\frac{\lambda^{2}}{R^{3}} a(\eta+\eta \theta)+\frac{\lambda^{3}}{R^{4}} a\left(\eta+\eta \theta+\eta \theta^{2}\right)+\ldots
\end{aligned}
$$

we see that, correspondingly, the engineers' share of gross output rises over time: $0, \eta, \eta+\eta \theta, \eta+\eta \theta+\eta \theta^{2}, \ldots$ Intuitively, as the cumulative contribution of engineers' human capital to plant productivity grows, the effects of the plant's initial productivity - essentially what an investor gets when he buys 


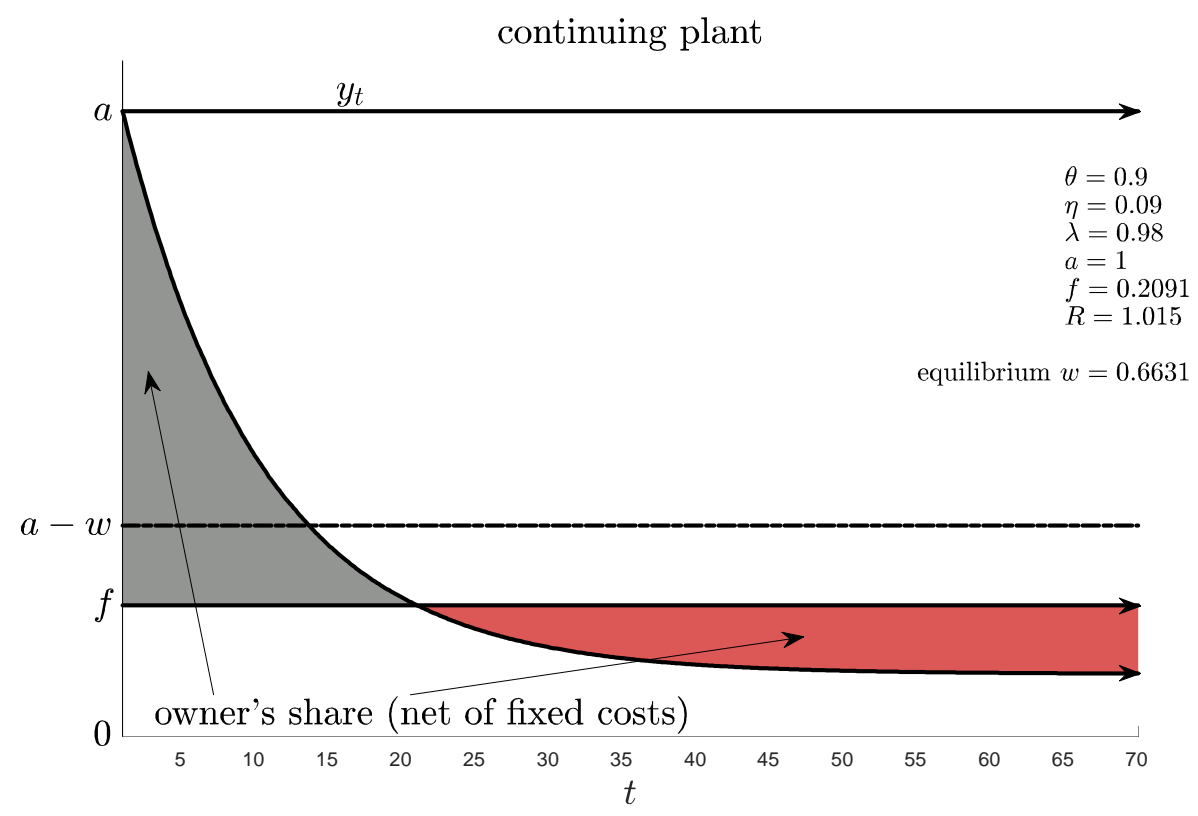

Figure 1: Horizons of owner's contribution to firm's revenues.

new plant - tails off. This gives us the clue to understand why an investing engineer borrows largely against near-term revenues.

In Figure 1, the downward sloping curve is the plant owner's share of the gross revenues $a$. Think of this as his rightful reward for his "contribution" to those revenues, stemming from the initial productivity $z=1$ of the plant that he paid to own. The grey and red heights are his shares net of the fixed cost $f$. With the parameters and equilibrium wage rate $w$ shown in the figure, in the near horizon his net share is positive (the grey area), as might be expected. But in the far horizon his net share has switched to become negative (the red area). This switch in sign is the key to understanding how low interest rates can harm investment and growth.

Take the case of constant returns to scale, $\theta+\eta=1$, so

$$
1-\eta-\eta \theta-\eta \theta^{2}-\ldots-\eta \theta^{T} \rightarrow 0 \text { as } T \rightarrow \infty .
$$

Thus, in this case, the downward sloping curve asymptotes to the horizontal axis and the plant owner's share of gross revenues, after subtracting the fixed cost that he must pay to continue production, unambiguously turns negative 
at some finite point in time. This begs the question: Why doesn't the plant owner shut down at this point and stop paying the fixed cost?

The reason is that, while the present wage bill equals the present value of engineers' current contribution to future revenues, past wage bills are sunk costs for the plant owner. As long as the present value of his future net cash flows, $(a-w-f)$ per unit of plant, is positive, the owner wants to continue with maintenance and production.

Because terms in the more distant future are more sensitive to a permanent change of interest rate, a fall in $R$ can reduce the engineer's borrowing capacity in (15). In particular, when $\theta+\eta=1$, we can solve (15):

$$
b=\frac{a}{R-\lambda \theta}-\frac{f}{R-\lambda} .
$$

Notice that the plant owner's share of gross output decreases with the horizon by factor $\lambda \theta$, because the owner in effect has to pay to engineers an increasing fraction of future output for their maintenance services. In contrast, fixed cost decreases with the horizon by factor $\lambda$. Since $\lambda>\lambda \theta$, the fixed cost has a longer horizon than the owner's share of gross output: a fall in $R$ increases the present value of the fixed cost proportionately more than the present value of the plant owner's share of gross revenues. This can reduce the initial value of plant to its owner and thereby reduce the engineer's borrowing capacity per unit of investment.

It will help our later discussion (in Section 7 below) if we make a brief side observation about the measurement of total investment. Suppose that at the time of investment, the engineer pays for the cost of the building as well as the plant, and raises funds by selling both to a saver. Then her total borrowing capacity per unit is the "corporate value"

$$
b+\frac{f}{R-\lambda}=\frac{a}{R-\lambda \theta},
$$

where here we have added to the original borrowing capacity $b$ the amount the saver is willing to pay for the building - the discounted value of the fixed costs $f$. Given that the engineer's total investment cost per unit,

$$
x+\frac{f}{R-\lambda},
$$

is higher than the original investment cost $x$ by the same amount, nothing changes. In particular, when $R$ falls, her total borrowing capacity might 
not increase as much as her total investment cost, which would increase the downpayment needed for investment. The corporate value to the saver would rise, but not by as much as the increase in the value of the building. Although the empirical implications are somewhat different when building value is included in borrowing capacity and investment cost (and perhaps more consistent with the data on total investment), the economic mechanism is the same.

Returning to the baseline model, we can aggregate across engineers and savers to obtain aggregate tool holdings $H_{t+1}$, financial asset holdings $D_{t+1} / R$, consumption $C_{t}$, and net worth of engineers and savers $\left(N_{t}^{E}\right.$ and $\left.N_{t}^{S}\right)$ :

$$
\begin{aligned}
(x-b) H_{t+1} & =\beta N_{t}^{E}, \\
\frac{D_{t+1}}{R} & =\beta N_{t}^{S} \\
C_{t} & =(1-\beta)\left(N_{t}^{E}+N_{t}^{S}\right) \\
N_{t}^{E} & =\pi^{E}[w+\lambda(x-b)] H_{t}+\pi^{S} D_{t}, \\
N_{t}^{S} & =\left(1-\pi^{E}\right)[w+\lambda(x-b)] H_{t}+\left(1-\pi^{S}\right) D_{t} .
\end{aligned}
$$

Equation (18a) says the aggregate capital value of tools equals the aggregate net worth of engineers after subtracting their consumption, and equation (18b) says the aggregate value of financial assets equals the aggregate net worth of savers after consumption. In equation (18c), aggregate consumption equals a fraction $1-\beta$ of the aggregate net worth of domestic residents. The aggregate net worth of engineers is the sum of the net worth of continuing and new engineers in equation $(18 d)$, and the aggregate net worth of savers is sum of the net worth of new and continuing savers in equation (18e).

The economy exhibits endogenous growth $G$ : along a steady state path, such that

$$
\begin{gathered}
\frac{H_{t+1}}{H_{t}}=\frac{D_{t+1}}{D_{t}}=\frac{C_{t+1}}{C_{t}}=G, \\
G N_{t}^{E}=N_{t+1}^{E}=\pi^{E} R^{E} \beta N_{t}^{E}+\pi^{S} R \beta N_{t}^{S}, \\
G N_{t}^{S}=N_{t+1}^{S}=\left(1-\pi^{E}\right) R^{E} \beta N_{t}^{E}+\left(1-\pi^{S}\right) R \beta N_{t}^{S} .
\end{gathered}
$$

Substituting out $\frac{N_{t}^{s}}{N_{t}^{E}}$, we find that $G$ solves

$$
G=\pi^{E} R^{E} \beta+\pi^{S} R \beta \frac{\left(1-\pi^{E}\right) R^{E} \beta}{G-\left(1-\pi^{S}\right) R \beta} .
$$


The growth rate depends on the rates of return for engineers and savers as well as on the wealth distribution between them.

Now, under certain conditions, we can verify our initial guess that no plant owner stops in the steady state: ${ }^{9}$

Proposition 1: If the fixed cost for operating a unit of plant is smaller than some critical value $f^{\text {critical }}$, then there is a steady state equilibrium in which

(a) no plant owner stops;

(b) the aggregate ratio of tools to plant stays one-to-one: $h=1$;

(c) all plant is maintained at the initial productivity level: $z=z^{*}=1$.

We call this a Pure Equilibrium with No Stopping, that exists when the model's parameters lie in the P-Region. Within this region:

\section{Proposition 2 (Pure Equilibrium with No Stopping):}

(a) For an open subset of the P-Region, in particular for $R$ and $\lambda$ not too far from unity, there is a pure equilibrium with no stopping such that an unexpected permanent drop in the interest rate $R$ leads to a lower steady state growth.

(b) Immediately following the drop in $R$, all agents (engineers and savers) can be strictly worse off.

In Appendix B, we derive a sufficient (but not necessary) condition for the existence of a pure equilibrium with no stopping:

$$
f<a \frac{R(1-\theta-\eta)}{\lambda(1-\theta)}\left[1-\frac{R-\lambda}{R}\left(\frac{R-\lambda \theta}{R}\right)^{\frac{\eta}{1-\theta-\eta}}\right] .
$$

In a pure equilibrium with no stopping, an unexpected permanent drop in the interest rate $R$ leads to a lower steady state growth rate $G$ if $\pi^{S}=0$ and

$$
f>a \frac{R-\lambda(\theta+\eta)}{R-\lambda \theta}-a \frac{G-\beta R \pi^{E}}{G-\beta \lambda \pi^{E}} \frac{\lambda \eta(R-\lambda)}{(R-\lambda \theta)^{2}} .
$$

\footnotetext{
${ }^{9}$ All proofs and details of derivations are in Appendix B. Proposition 2(b) is demonstrated numerically.
} 
These inequalities are mutually consistent if $R$ and $\lambda$ are not too far from unity. ${ }^{10}$

To understand why a fall in $R$ can stifle investment and growth, consider the effect on the equation for gross investment:

$$
\begin{gathered}
\text { gross investment }\left(H_{t+1}\right) \downarrow= \\
\text { saving rate }(\beta) \times \frac{\text { net worth of engineers }\left(N_{t}^{E}\right) \uparrow}{\text { investment cost }(x)-\text { borrowing capacity }(b) \downarrow}
\end{gathered}
$$

Although engineers' net worth increases with a fall in $R$ (primarily through a rise their wage $w$ ), a decrease in their borrowing capacity may have a larger negative effect on investment, and therefore on growth. Much of the macro finance literature (including Bernanke and Gertler (1989) and Kiyotaki and Moore (1997)) has emphasized effects on net worth in the numerator. Here we are focussing on the effect on borrowing capacity in the denominator.

In terms of welfare, a fall in $R$ can make all domestic agents (engineers and savers) strictly worse off. It is not surprising that savers may be worse off with a lower rate of return on financial assets. The reason why engineers may be worse off is that their leveraged rate of return

$$
R^{E}=\frac{w+\lambda(x-b)}{x-b}
$$

can decrease through a drop in borrowing capacity $b$. Appendix B derives the welfare of engineers and savers immediately after an unanticipated and permanent fall in the interest rate, taking into account the stochastic arrival of future investment opportunities.

\footnotetext{
${ }^{10}$ If $\pi^{S}>0$, then a sufficient condition for the growth rate to fall with an unexpected permanent drop in the interest rate is that

$$
\lambda(1-\theta) f>(R-\lambda)^{2} x+\lambda(1-\theta-\eta) a .
$$

This condition guarantees that the rate of return for an investing engineer is an increasing function of the interest rate. See Appendix B. Because - unlike (21) - this condition involves $x$, it cannot be readily juxtaposed with (20).
} 


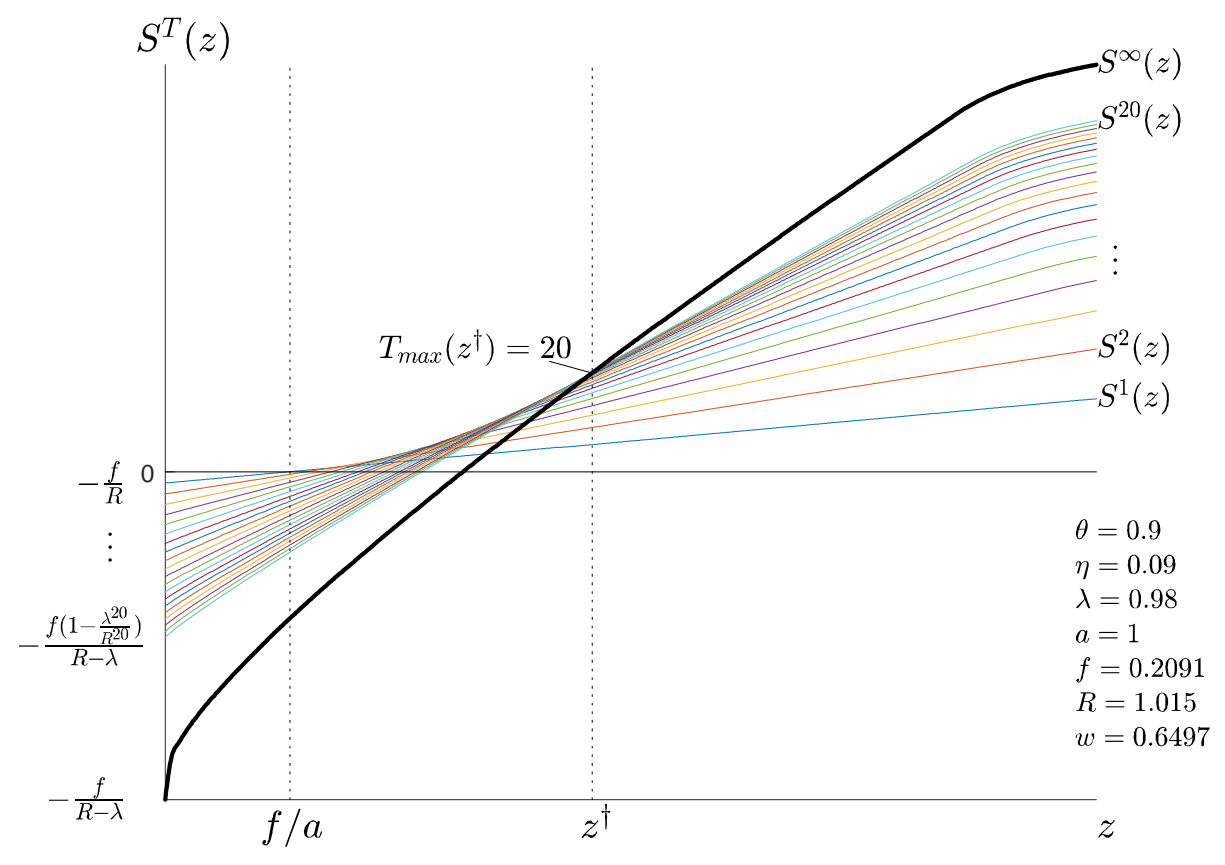

Figure 2: Value functions and stopping horizons.

\section{Mixed Equilibrium}

What happens if the condition for the pure equilibrium with no stopping is violated, i.e. the fixed cost is higher than the critical level $f^{\text {critical }}$ in Proposition 1? It turns out there is a clear dichotomy for the plant owner between continuing forever and stopping after a finite number of periods (for a given wage and interest rate):

\section{Lemma:}

(a) If the current plant productivity $z$ is below some cutoff value, $z^{\dagger}$, it is optimal for the plant owner to stop after, say, $T_{\max }(z)<\infty$ periods.

(b) If $z$ is above $z^{\dagger}$, it is optimal to continue forever.

(c) The cutoff value $z^{\dagger}$ increases with the fixed cost $f$. It is also a function of the wage rate and the interest rate.

In Figure 2, we plot the per-unit plant value, as a function of the current productivity $z$, for a given wage $w$ and interest rate $R$, and for different stopping horizons $T$. The function $S^{\infty}(z ; w, R)$ is the value when the plant 


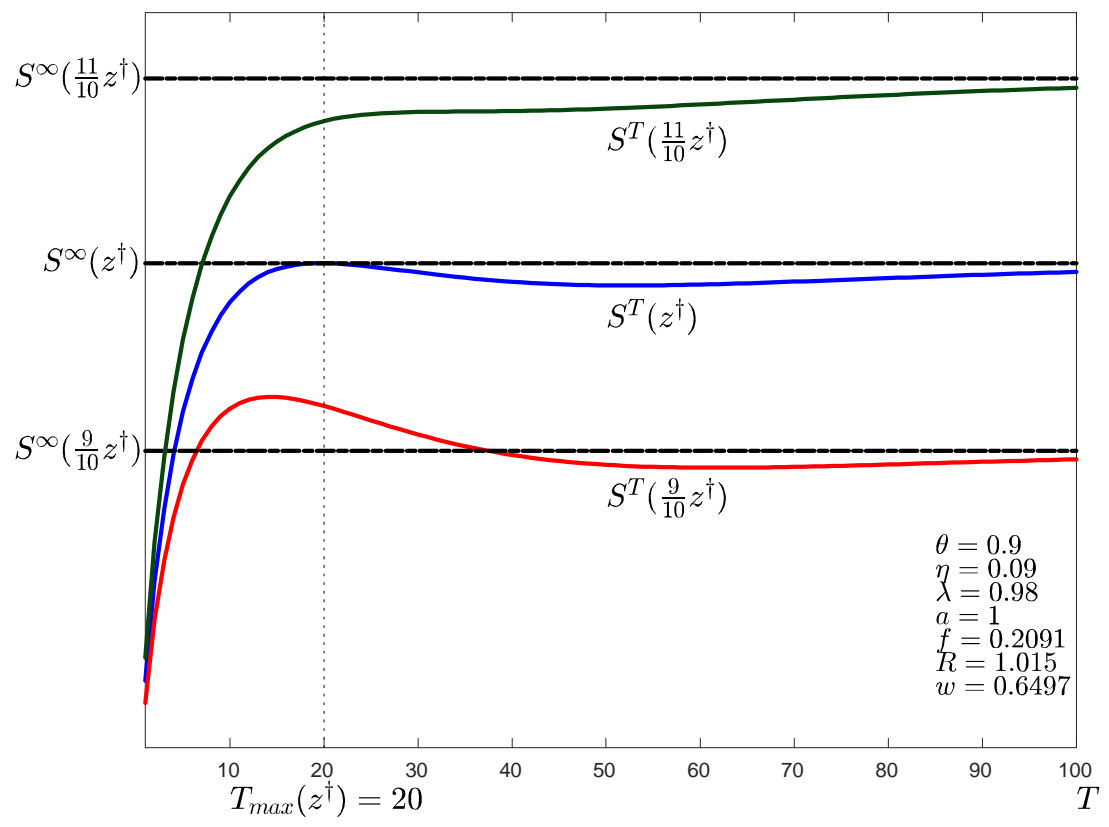

Figure 3: Value functions $S^{T}(z)$ near threshold $z^{\dagger}$ where plant owner is indifferent between stopping in a finite horizon or continuing forever.

owner chooses to maintain production forever. The upper envelope of all these functions is the value function of plant $V(z ; w, R)$ with an optimal choice of stopping (including non-stopping). If $z$ is very low, then it is optimal for the owner to shut down the plant immediately. If $z$ is higher than $f / a$, then it is optimal to continue at least for one period because, minimally, the plant owner can earn profit by hiring no engineers. Thus, if $z$ is higher than $f / a$ but lower than $z^{\dagger}$, the owner will shut down plant not immediately but in a finite horizon, where the horizon is an increasing function of $z$. At $z=z^{\dagger}$, the plant owner is indifferent between continuing forever and shutting down in a finite time (for this numerical example, in 20 periods). If $z$ is higher than $z^{\dagger}$, the plant owner will continue forever - that is, until the plant dies exogenously.

In Figure 3, we plot $S^{T}(z ; w, R)$ as a function of horizon $T$ for three different levels of plant productivity, $z=0.9 z^{\dagger}, z^{\dagger}$, and $1.1 z^{\dagger}$. If plant productivity is relatively low, at $z=0.9 z^{\dagger}$, then the value reaches a maximum with finite 
horizon: for our example, around $T=15$ so that the owner will shut down in 15 periods. If plant productivity is exactly equal to $z^{\dagger}$, then the plant owner is indifferent between shutting down in 20 periods $(T=20)$ and continuing forever $(T=\infty)$. If plant productivity is relatively high, at $z=1.1 z^{\dagger}$, then the owner finds that $S^{\infty}(z ; w, R)>S^{T}(z ; w, R)$ for any finite $T$ so that he will continue forever.

In general equilibrium, the wage rate $w$ and the value of $z^{\dagger}$ are endogenous. The aggregate dynamics of net worth, tools, financial asset holdings and consumption are still described by equations $(18 a)-(19)$ but, in contrast to Proposition 1, there is now stopping:

Proposition 3: If the fixed cost for operating a unit of plant $f$ is larger than a critical value $f^{\text {critical }}$ from Proposition 1 , then there is an equilibrium in which:

(a) Plant owners are initially indifferent between stopping in finite time $T$ and continuing forever: $z^{\dagger}=1$; in particular,

(i) if the initial output is larger than the fixed cost, $a>f$, then plant owners are initially indifferent between stopping in finite time $T \geq 1$ and continuing forever, whereas

(ii) if the initial output is smaller than the fixed cost $(a<f)$, then plant owners are initially indifferent between stopping immediately $(T=0)$ and continuing forever;

(b) The aggregate ratio of tools-to-plant is larger than one-to-one for continuing plant: $h>1$;

(c) With decreasing returns to scale, $\theta+\eta<1$, the productivity of continuing plant increases over time, converging to some $z^{*} \in(1, \infty)$; whereas with constant returns to scale, $\theta+\eta=1$, the productivity of continuing plant grows at some constant rate $g>1$;

(d) If $f \in\left(f^{\text {critical }}, a\right)$, then the productivity of stopping plant decreases over time;

(e) There is no equilibrium where all plant stops in finite time.

We call this a Mixed Equilibrium, that exists when the model's parameters lie in the M-Region (the complement of the P-Region). Within this region, the initial productivity is exactly equal to the critical productivity $z^{\dagger}$ for shutting down, so that some plant is stopped and some continues forever (modulo depreciation). Because the owners of stopping plant do not hire many tools, the aggregate ratio of tools to plant is larger than one-to-one for 
continuing plant: $h>1$. With an abundant supply of tools per plant, continuing plant keeps improving in productivity. If the maintenance technology has decreasing returns to scale, $\theta+\eta<1$, the productivity of continuing plant converges to some finite steady state level $z^{*}$. If the maintenance technology has constant returns to scale, $\theta+\eta=1$, the productivity of continuing plant grows at some rate $g>1$. Therefore, even though all plant is homogeneous when new, some plant improves in productivity while the rest fails to maintain productivity and eventually exits (or immediately exits if $a<f$ ). That is, firms evolve heterogeneously in their productivity and output even though they start off homogenous and face no idiosyncratic shocks. ${ }^{11}$

If all plant were to stop in finite time, the market for tools (engineers) would be in excess supply: because of exit the quantity of active plant would be smaller than tools, plus there would be little demand for tools by plant owners who are planning to stop, so the equilibrium wage rate for tools would fall to the point where at least some plant owners switch strategy and continue forever.

For the Mixed Equilibrium we have limited analytical results, and derive our findings by numerical simulations:

\section{Proposition 4 (Mixed Equilibrium)}

An unexpected permanent drop in the interest rate $R$ can lead to a lower steady state growth rate $G$.

In Figure 4, we illustrate how nine endogenous variables depend on the interest rate $R$ in the range between 1 and 1.03 (between 0 and $3 \%$ net) in steady state equilibrium. We choose the parameters so that the economy is in the pure no-stopping region (P-Region) for $R \in[1.015,1.03]$ and in the mixed equilibrium region (M-Region) for $R \in[1,1.015)$.

\footnotetext{
${ }^{11}$ This is different from the standard approach taken by Jovanovic (1981) and Hopenhayn (1992) in which initial heterogeneity and/or subsequent heterogeneity (induced by idiosyncratic shocks) are essential to firm dynamics. Even allowing for idiosyncratic shocks (see Section 5), our approach may provide a different perspective on firm dynamics. Our model is more closely related to, for example, Atkeson and Burnstein (2010), Clementi and Palazzo (2016), Ericson and Pakes (1995), Klette and Kortum (2004), and Rossi-Hansberg and Wright (2007), all of which stress the interaction between heterogeneity, idiosyncratic shocks, and investment.

Griliches and Regev (1995) presents evidence that the productivity of many firms starts deteriorating before exiting, calling it the "shadow of death."
} 

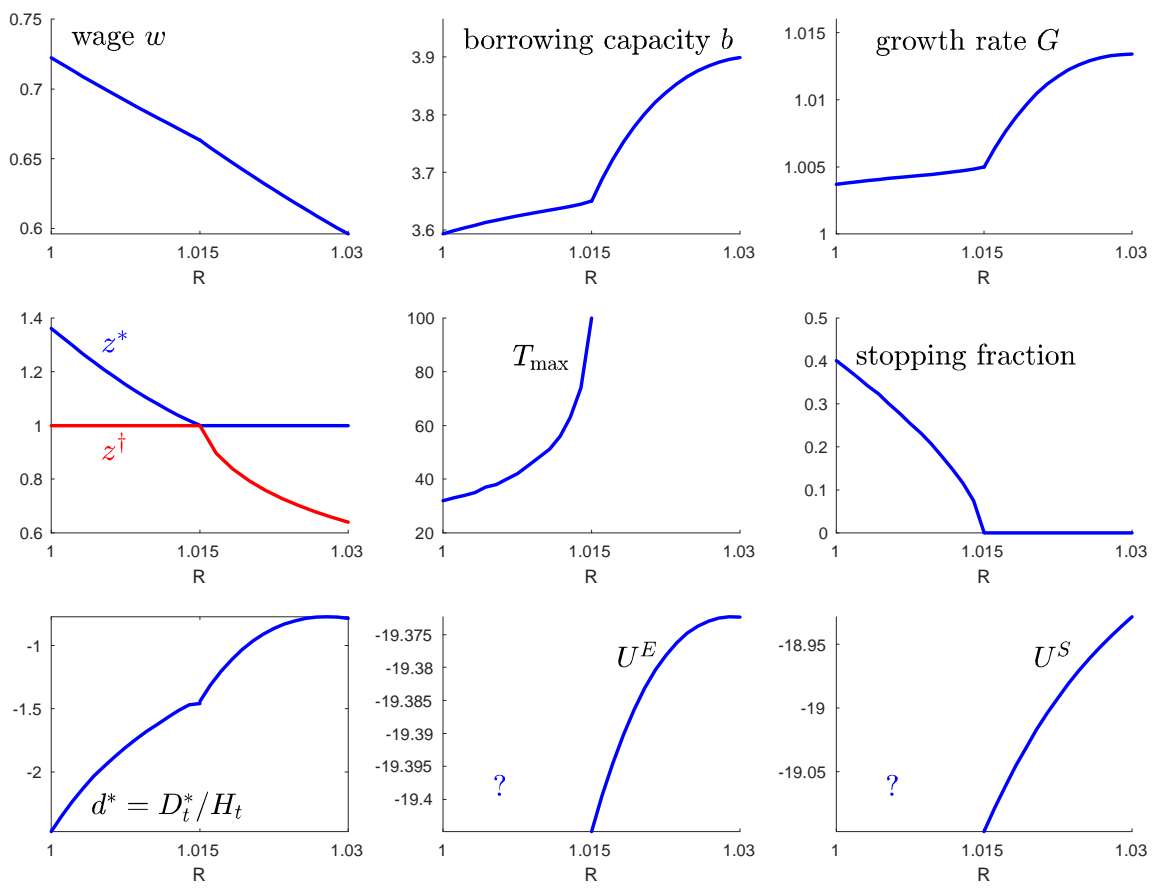

Figure 4: Lower real rate, credit horizons and stagnation.

\begin{tabular}{|l|l|l|}
\hline$\theta$ & share of past productivity in maintenance & 0.9 \\
\hline$\eta$ & share of engineer in maintenance & 0.09 \\
\hline$\lambda$ & one minus depreciation rate & 0.98 \\
\hline$a$ & productivity & 1 \\
\hline$f$ & fixed cost & 0.2091 \\
\hline$x$ & investment cost per plant & 6.127 \\
\hline$\beta$ & utility discount factor & 0.92 \\
\hline$\pi^{E}$ & probability of staying to be engineer & 0.7 \\
\hline$\pi^{S}$ & probability of saver to become engineer & 0.1 \\
\hline
\end{tabular}

In the top-left panel of Figure 4, the wage rate is a decreasing function of the interest rate because an engineer's contribution to future output through maintenance work has a long horizon. In the top-middle panel, the engineer's borrowing capacity increases with the interest rate because the plant owner's share of output has a shorter duration than fixed cost. Notice that this effect 
is smaller in the M-Region, with an endogenous adjustment of the fraction of stopping plant (extensive margin) and of the stopping time (intensive margin). In the top-right panel, the economy's growth rate is an increasing function of interest rate, albeit that the sensitivity is weaker in the M-Region.

In the middle-left panel, the asymptotic plant productivity $z^{*}$ equals 1 in the P-Region and is a decreasing function of $R$ in the M-Region. The threshold plant productivity for continuing and stopping $z^{\dagger}$ equals 1 (initial productivity) in the M-Region (consistent with plant owners being indifferent between stopping and continuing) and is a decreasing function of $R$ in the $\mathrm{P}$ Region (consistent with plant owners gaining more indirectly from the lower wage rate than hurting directly from the higher interest rate). In the middlemiddle panel, the number of periods before stopping $\left(T^{\max }\right)$ is finite and is an increasing function of $R$ for those who choose to stop in the M-Region. In the P-Region, no-one stops and $T^{\max }=\infty$. In the middle-right panel, the fraction of stopping plant is zero in the P-Region and is a decreasing function of $R$ in the M-Region.

In the bottom-left panel, we see that the net financial asset holdings of foreigners is negative, i.e., domestic residents lend to foreigners in net terms. Despite the foreign interest rate being lower than the subjective interest rate $(R<1 / \beta)$, the domestic economy has a shortage of means of saving due to the financial friction and needs to make use of foreign bonds. With a lower interest rate, the financing constraint is tighter and domestic savers hold a yet larger position in foreign bonds. In the bottom-middle panel, the welfare of a representative engineer (who holds the average net worth of engineers) is an increasing function of $R$ in the P-Region, i.e., welfare is lower with lower $R$. In our example, when $R$ falls from 1.03 to 1.015 unexpectedly and permanently, the welfare of a representative engineer falls by the equivalent of a $0.12 \%$ permanent fall in consumption. We do not have comparable results for the M-Region, because one cannot define simply what is meant by a representative engineer. In the bottom-right panel, the welfare of savers is an increasing function of $R$ in the P-Region. The effect on savers is larger: when $R$ falls from 1.03 to 1.015 unexpectedly and permanently, their welfare falls by the equivalent of a $1.2 \%$ permanent fall in consumption. 


\section{Extension: idiosyncratic uncertainty}

In the model thus far, even though plant produces output deterministically, we find that equilibrium plant dynamics emerge in the mixed equilibrium where some plant owners hire insufficient engineers to maintain plant productivity and slowly exit. In this section, we further connect our theory to the literature on plant dynamics by introducing idiosyncratic shocks to plant productivity. We study how these shocks affect plant owners' decisions on maintenance and exit.

Let us modify the production technology (4) to:

$$
\left.\begin{array}{c}
\text { plant of productivity } z \\
h \text { tools } \\
f \text { goods }
\end{array}\right\} \rightarrow\left\{\begin{array}{c}
y=a z \text { goods } \\
\lambda \text { plant of productivity } z^{\prime}=\epsilon z^{\theta} h^{\eta} \\
\lambda h \text { tools }
\end{array}\right.
$$

where $\epsilon$ is an idiosyncratic productivity shock, i.i.d. across plant and over time. It follows a lognormal distribution whose mean is normalized to one:

$$
\log \epsilon \sim N\left(-\frac{\sigma^{2}}{2}, \sigma^{2}\right)
$$

The value of a unit of plant of productivity $z$ at the end of a period is

$$
V(z)=\frac{1}{R}\left\{0, \max _{h}\left[a z-w h-f+\lambda E V\left(\epsilon z^{\theta} h^{\eta}\right)\right]\right\} .
$$

Compared with the plant value without productivity uncertainty, the only difference is that the continuation value of the firm is subject to the idiosyncratic shock, $\epsilon$.

To illustrate the effect of the idiosyncratic shock, we continue with the numerical example in the previous sections $(\theta=0.9, \eta=0.09, \lambda=0.98$, $a=1, f=0.2091, R=1.015$, and $w=0.6497)$.

When the productivity shock has a small variance, the owner's productivity maintenance decision is similar to that in a deterministic environment. Figure 5 illustrates the maintenance decision, $h$, and the expected productivity in the following period, $z^{\prime}$, when idiosyncratic shocks have a small dispersion, $\sigma=0.0001$. In this case, there still exists a dichotomy between those plants that the owners intend to exit and those that the owners intend to continue. If current plant productivity $z$ is below a critical value, $z^{\dagger}$, the plant owner does not hire much maintenance service and most likely exits in 

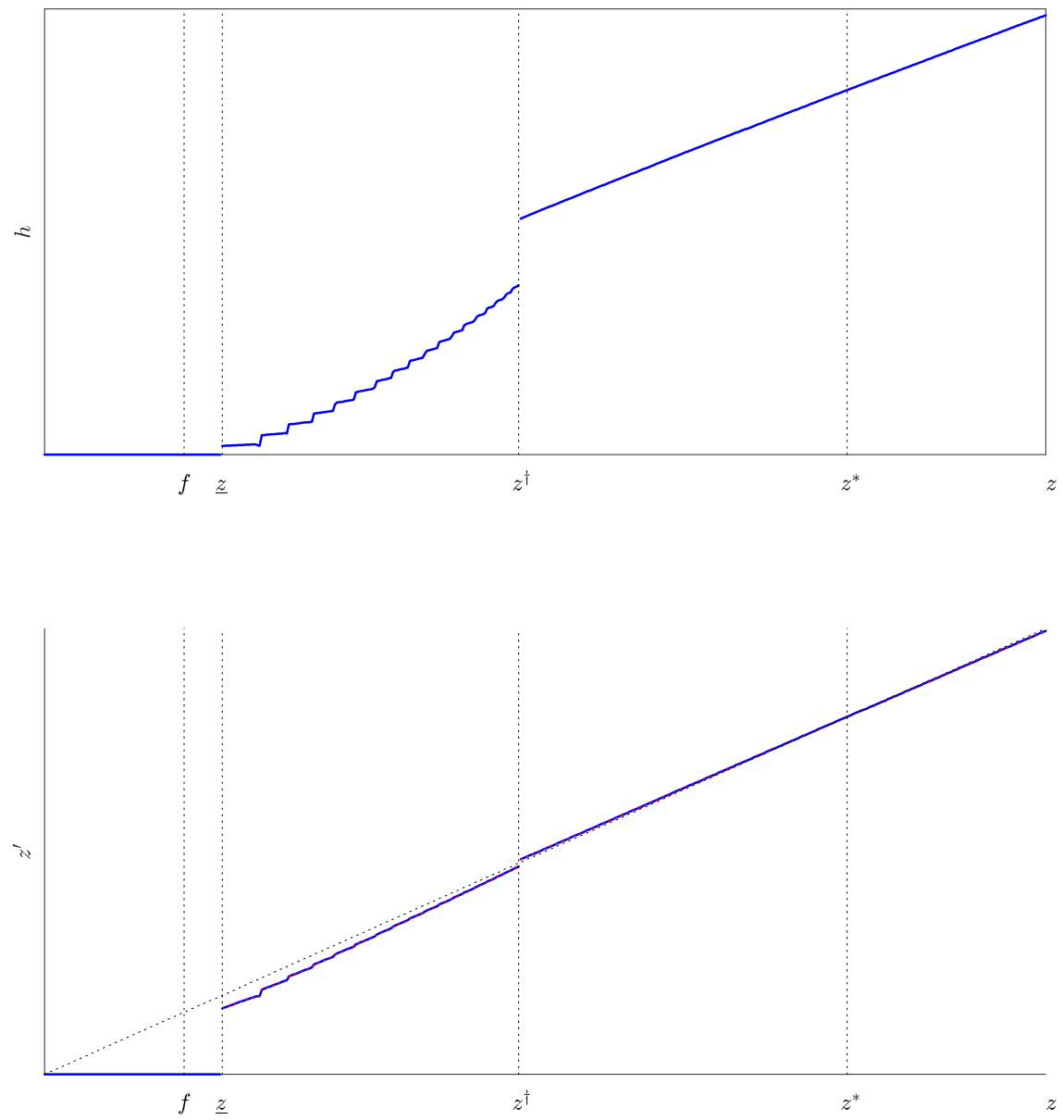

Figure 5: Productivity maintenance with small idiosyncratic risk, $\sigma=0.0001$. 
random finite number of periods but not immediately. If $z$ is above $z^{\dagger}$, the plant owner hires distinctively larger engineering service and continues operating until the plant dies exogenously, unless extremely unlucky idiosyncratic shocks bring down the plant productivity below $z^{\dagger}$.

At $z=z^{\dagger}$, the plant owner has two distinct optimal levels of maintenance: his expected value from maintenance has twin peaks. If he chooses the slow exit strategy, he saves some maintenance costs but receives less profit from future production. If he chooses to continue operating the plant for the long haul, he pays more to maintain the plant and in return receives more profit from future production. The maintenance input $h$ and expected productivity $z^{\prime}$ increase discontinuously as current productivity $z$ moves up across the critical value $z^{\dagger}$, as the plant owner finds it optimal to operate the plant for the long haul.

Figure 6 illustrates the plant owner's maintenance decision, $h$, and productivity distribution in the following period, $z^{\prime}$, when the idiosyncratic shocks are large, $\sigma=0.02$. In the figure on realized productivity, $z^{\prime}$, the blue curve represents the expected productivity in the following period. The red curves represent the realized productivity that are three standard deviations above or below the expected value. With large productivity shocks, the dichotomy between exiting and continuing is blurred: the plant owner's maintenance input is a continuous function of the current plant productivity $z$. This is because even when the plant owner would like to improve productivity, a large negative idiosyncratic shock may still lead to a low productivity. This smooths the plant owner's expected payoff from maintenance and makes it single-peaked.

\section{Policy}

When the competitive equilibrium is not efficient, it is natural to ask whether the government could improve welfare through taxes and subsidies. The sole departure from the Arrow-Debreu model in our framework is the nonexclusivity constraint: a saver who buys plant from an engineer (the creditor who lends to the engineer against the plant) cannot prevent this engineer from working for another plant in future. In effect, we are supposing it is impossible to keep track of each engineer's trading history.

However, because the plant is easy to locate, it may be possible for the 

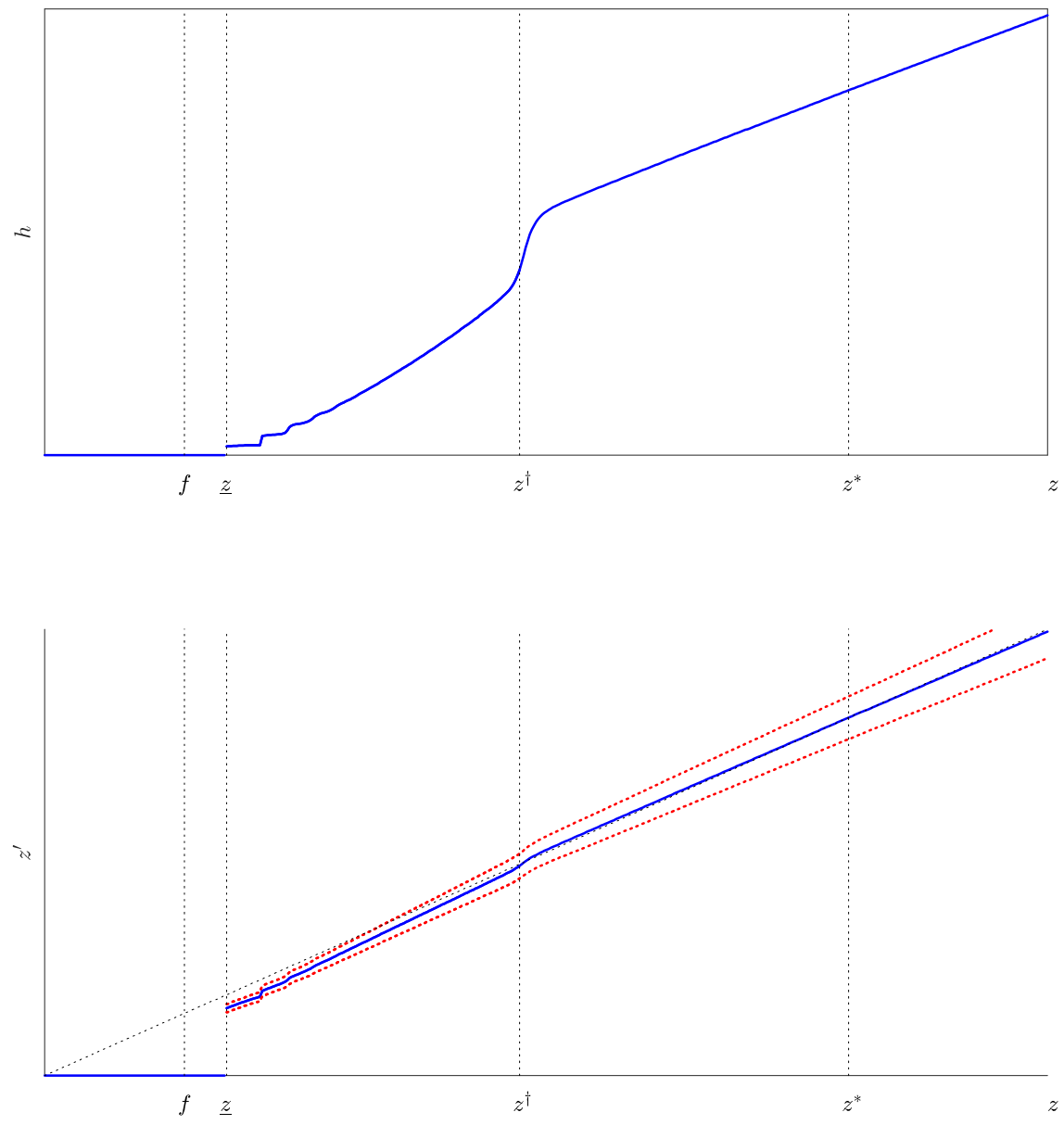

Figure 6: Productivity maintenance with large idiosyncratic risk, $\sigma=0.02$. 
government to keep track of how much the plant owner buys the maintenance services of engineers - even though government does not know the identity of engineers. Suppose government can tax the payroll for engineers of each plant owner at rate $\tau$, and use the tax revenue to subsidize engineers by $s$ per unit of investment. We ignore idiosyncratic shocks to the realized productivity after maintenance and restrict our attention to the steady state of a Pure Equilibrium with No Stopping (the parameters lie in Region P). We assume the government's budget is balanced:

$$
\tau w H=s I=s(G-\lambda) H .
$$

$\tau w H$ is the payroll tax revenue and $s I=s(G-\lambda) H$ is the investment subsidy.

Because plant owners equate the marginal contribution of engineers' expertise to the wage cost including the payroll tax, we have

$$
(1+\tau) w=w^{o}=\frac{\eta \lambda}{R-\lambda \theta} a
$$

where $w^{o}$ and $w$ are wage rates for the plant owners and engineers. The last equality comes from (12) with $h_{t}=z_{t}=1$ in the steady state. Notice that the payroll tax does not affect the wage cost to the plant owner, but reduces the wage rate for engineers. Together, these equations imply that

$$
s=\frac{\tau}{1+\tau} \frac{w^{o}}{G-\lambda} .
$$

The price of new plant is unchanged at

$$
b=V(1)=\frac{a-w^{o}-f}{R-\lambda} .
$$

The budget constraint of the agent becomes

$$
c_{t}+(x-b-s) i_{t}+\frac{d_{t+1}}{R}=w h_{t}+d_{t}
$$

Solving for the individuals' choices and aggregating across agents, we get

$$
\begin{aligned}
& (x-b-s) H_{t+1}=\beta \pi^{E}[w+\lambda(x-b-s)] H_{t}+\beta \pi^{S} D_{t}, \\
& \frac{D_{t+1}}{R}=\beta\left(1-\pi^{E}\right)[w+\lambda(x-b-s)] H_{t}+\beta\left(1-\pi^{S}\right) D_{t} .
\end{aligned}
$$


As in (19), the steady state growth rate becomes

$$
G=\beta R^{E}\left[\pi^{E}+\frac{\pi^{S}\left(1-\pi^{E}\right) R \beta}{G-\left(1-\pi^{S}\right) R \beta}\right],
$$

where the rate of return for the engineer to invest with maximum leverage is

$$
\begin{aligned}
R^{E} & =\frac{w+\lambda(x-b-s)}{x-b-s} \\
& =\frac{w^{o}}{(1+\tau)(x-b)-\tau \frac{w^{o}}{G-\lambda}}+\lambda
\end{aligned}
$$

using $(23,24)$. Then we learn that the rate of return from investment changes with the tax and subsidy in the neighborhood of $\tau=0$ as

$$
\begin{aligned}
\frac{\partial R^{E}}{\partial \tau} & =\frac{w}{(x-b)^{2}}\left[\frac{w}{G-\lambda}-(x-b)\right] \\
& =\frac{w}{(x-b)(G-\lambda)}\left[\left(\frac{w}{x-b}+\lambda\right)-G\right] \\
& =\frac{w}{(x-b)(G-\lambda)}\left(R^{E}-G\right) .
\end{aligned}
$$

Because the growth rate of the economy $G$ is the weighted average of the growth rate of engineers, $\beta R^{E}$, and savers, $\beta R$, where $R^{E}>R$ in our economy, we learn $G<\beta R^{E}<R^{E}$ and

$$
\frac{\partial R^{E}}{\partial \tau}>0
$$

The equilibrium growth rate in (25) solves

$$
\beta \pi^{E} R^{E}=\frac{G}{\pi^{E}+\frac{\pi^{S}\left(1-\pi^{E}\right) \beta R}{G-\left(1-\pi^{S}\right) \beta R}} .
$$

Since the RHS is an increasing function of $G$, we have

$$
\frac{\partial G}{\partial \tau}>0
$$

Thus the introduction of this tax and subsidy scheme increases steady state investment, and therefore growth, relative to the laissez-faire. 
To get a handle on the overall effect of this policy intervention on the welfare of the domestic economy, we define a measure of social welfare as the population-weighted average of the expected discounted utilities of engineers and savers. The point is that we need to account for any short-term losses (as well as gains) at the time the policy is introduced, in addition to the longer-term benefits of higher growth. We show in Appendix B that, by this measure, social welfare goes up.

Why? In our framework, because of the non-exclusivity constraint (an individual engineer can work for any plant owner without getting traced by her creditors ex post), the engineers each face a borrowing constraint ex ante at the time of investment. By taxing the payroll of the plant owners, the government in effect acts as a collective creditor - the receipts from which, when fed back to the engineers, subsidize investment. It is as if, through the government intervention, the engineers as a group promise to pay back a portion of each others' debt obligations. ${ }^{12}$ Crucial to the effectiveness of this policy is the government's ability to keep an eye on all the various units of plant (presumed to be fixed in buildings), to tax the owners' payments to engineers, in a context where the identities of the engineers themselves cannot be traced.

\section{Final Speculative Remark}

It has been observed that during the credit and asset price booms in Japan in the late 1980s and in southern Europe in the early 2000s, the aggregate values of credit and assets grew faster than productive capacity. (See Hoshi and Ito (2020) and Gopinath, Kalemi-Ozcan, Karabarbounis and Villegas-Sanchez (2017)). In the macro-finance literature, many authors have observed that credit booms associated with asset price booms are often followed by financial crises. (See for example, Reinhart and Rogoff (2008), Schularick and Taylor (2012) and Jorda, Schularick and Taylor (2018).) These authors consider such booms as being associated with excessive expansion of credit and assets values. Our model provides a different perspective.

\footnotetext{
${ }^{12}$ In our model, the burden of the payroll tax is entirely borne by the engineers, because plant owners face unchanged wage costs and plant prices. In this sense, it is the most favorite case for the tax-subsidy scheme to boost the growth rate. In more general model, the tax burden would be split between the engineers and plant owners.
} 
Consider again a Pure Equilibrium with No Stopping (the parameters lie in Region $\mathrm{P}$ ) and assume the real interest rate $R$ is constant from date $t$ onward. Suppose, at the time of investment, engineers pay the cost of the building as well as the cost of plant and human capital, and raise funds by selling both building and plant to savers. As we pointed out in Section 3, the economics are the same as when buildings are rented, but the measurement of total investment is different.

We need to model the supply of buildings. For clarity, assume there are foreign builders who have an alternative use of a building that yields $f$ every period and that a building depreciates at the same rate as plant. So the building price at the end of each period is

$$
q=\frac{f}{R}+\frac{\lambda f}{R^{2}}+\frac{\lambda^{2} f}{R^{3}}+\ldots=\frac{f}{R-\lambda} .
$$

Competitive foreign builders have enough capacity to satisfy the building demand of the domestic economy at their marginal cost $q \cdot{ }^{13}$

The unit cost of investment for an engineer is $x+q$. Her borrowing capacity per unit of investment is

$$
b+q=\frac{a-w-f}{R-\lambda}+\frac{f}{R-\lambda}=\frac{a-w}{R-\lambda} .
$$

The measured value $I_{t}^{m}$ of total investment now includes the value of buildings:

$$
I_{t}^{m}=(x+q) I_{t}=(x+q)\left(K_{t+1}-\lambda K_{t}\right) .
$$

From the current account, the gap between domestic absorption (consumption plus investment) and output equals the net accumulation of foreign debt

$$
C_{t}+(x+q) I_{t}-Y_{t}=\frac{D_{t+1}^{*}}{R}-D_{t}^{*},
$$

\footnotetext{
${ }^{13}$ In the baseline model, $f$ is a fixed cost (or rent paid to a foreign landlord) and is subtracted from output to compute GDP. In this section, because the building is owned by domestic agents, we do not subtract $f$ from GDP and include the building purchase price in total investment. Any difference between the building purchase price and the construction cost is the profit of foreign builders.

We introduce foreign builders to make this alternative model as comparable to our baseline model as possible. If builders were domestic agents, we would need to take into account the impact of their income and wealth on the domestic economy - although we do not expect this would qualitatively change our findings.
} 
where $Y_{t}=a K_{t}$ is domestic output.

As in the baseline model, consumption is proportional to aggregate net worth:

$$
\begin{aligned}
C_{t} & =(1-\beta) N_{t} \\
& =(1-\beta)\left\{[a+\lambda(x+q)] K_{t}-D_{t}^{*}\right\} .
\end{aligned}
$$

Aggregate net worth in braces is domestic output plus the value of plant and building after production, net of foreign debt.

Aggregate capital in the next period equals the ratio of net worth of engineers (after consumption) and the downpayment for investment;

$$
\begin{gathered}
K_{t+1}=\frac{\beta N_{t}^{E}}{x-b} \\
=\frac{\beta}{x-b}\left\{\pi^{E}[w+\lambda(x-b)] K_{t}+\pi^{S}\left[(a-w+\lambda(b+q)) K_{t}-D_{t}^{*}\right]\right\} .
\end{gathered}
$$

The first term in braces is the net worth of the continuing engineers; the second term is the net worth of the new engineers who have plant and building from the previous period, leveraged by foreign debt.

Suppose the economy was in steady state at date $t-1$, for a presumed constant interest rate. Unexpectedly at date $t$, the interest rate falls permanently. If the parameters satisfy the condition of Proposition 2(a), then the long-run growth rate falls. Figure 7 shows the movement of the aggregate values of investment, consumption, output and foreign debt holdings, when the real interest rate unexpectedly falls from $2.5 \%$ to $1.5 \%$ permanently at date 5 .

Initially, the measured value $I_{t}^{m}$ of total investment value increases because buildings are more expensive and the new engineers have greater net worth due to capital gains on the buildings they hold from the previous period. Consumption increases too, with the greater net worth. Because domestic absorption (investment and consumption) expands more than output, foreign debt rises rapidly during the transition. Despite the boom, the growth rate of plant and human capital eventually falls. As the boom fades, the slower growth of productive capacity, exacerbated by a larger foreign debt-to-income ratio, causes secular stagnation. ${ }^{14}$

\footnotetext{
${ }^{14}$ This sequence of events may correspond better to southern European countries in the early 2000s than to Japan in late 1980s, insofar as the fall in their interest rate was fast and considered to be permanent.
} 

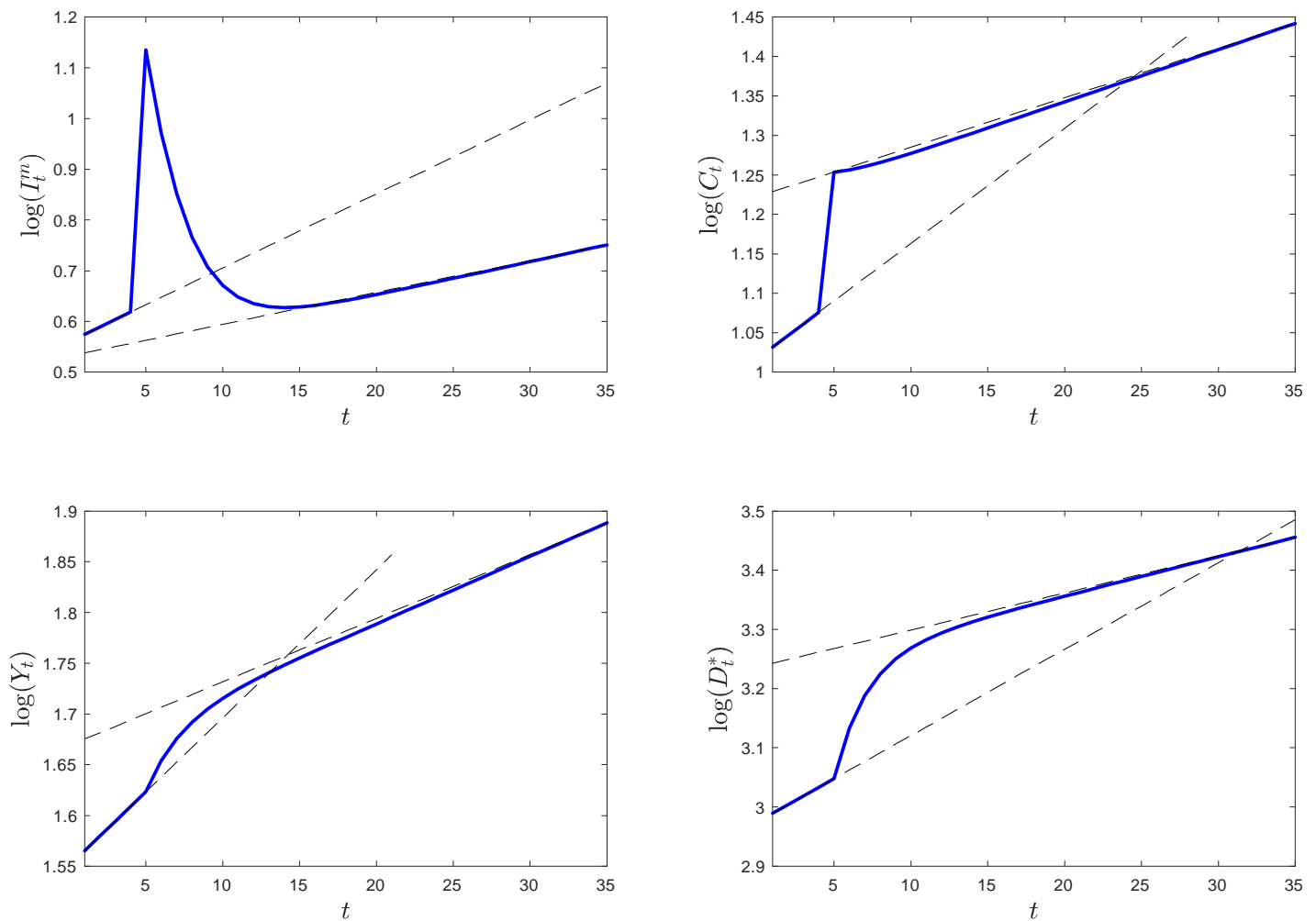

Figure 7: Impluse Response to Permanent Fall in Interest Rate 
From this perspective, a persistently lower real interest rate leads to an initial credit and asset value boom, but stagnation in the long run, not because the boom was excessive, but because the underlying growth rate of the productive capacity declined. ${ }^{15}$

\footnotetext{
${ }^{15}$ Another, complementary, perspective to ours is that credit and asset price booms associated with lower interest rates tend to lead to greater misallocation of capital when the domestic financial system is underdeveloped. See, for example, Aoki, Benigno and Kiyotaki (2007), Reis (2013), Gopinath, Kalemi-Ozcan, Karabarbounis and Villegas-Sanchez (2017), and Asriyan, Martin, Vanasco and Van der Ghote (2020).
} 


\section{References}

Allen, Franklin. 1985. "Repeated Principal-Agent Relationships with Lending and Borrowing." Economic Letters, 17(1-2): 27-31.

Aoki, Kosuke, Gianluca Benigno, and Nobuhiro Kiyotaki. 2007. "Capital Flows and Asset Prices," in NBER International Seminar on Macroeconomics, edited by R. Clarida and F. Giavazzi, Chicago: Chicago University Press (2007), 175-216.

Arrow, Kenneth. 1962. "Economic Implications of Learning by Doing." Review of Economic Studies, 29(3): 155-173.

Asriyan, Vladimir, Alberto Martin, Victoria Vanasco and Alejandro Van der Ghote. "Interest Rates, Asset Prices and the Allocation of Credit." Presented at Barcelona GSE Research Webinar: Asset Prices, Finance and Macroeconomics in June 2020.

Atkeson, Andrew, and Ariel Burnstein. 2010. "Innovation, Firm Dynamics and International Trade." Journal of Political Economy, 118(3): 433-484.

Attar, Andrea, Thomas Mariotti and François Salanié. 2011. "Nonexclusive Competition in the Market for Lemons." Econometrica, 79(6): 18691918.

Aumann, Robert, Yitzhak Katznelson, Roy Radner, Robert Rosenthal, and Benjamin Weiss. 1983. "Approximate Purification of Mixed Strategies." Mathematics of Operations Research, 8(3), 327-341.

Bernanke, Ben, and Mark Gertler. 1989. "Agency Costs, Net Worth, and Business Fluctuations." American Economic Review, 79(1): 14-31.

Böhm-Bawerk, Eugen. 1889. Positive Theory of Capital: Volume 2 of Capital and Interest. English Translation. Liberty Press, South Holland, Illinois, 1959.

Clementi, Gian Luca, and Berardino Palazzo. 2016. "Entry, Exit, Firm Dynamics, in Aggregate Fluctuations." American Economic Journal: Macroeconomics 8(3): 1-41.

Cole, Harold, and Narayana Kocherlakota. 2001. "Efficient Allocations with Hidden Income and Hidden Storage." Review of Economic Studies, 68(3): 523-542.

De la O, Ricardo, and Sean Myers. 2021. "Subjective Cash Flow and Discount Rate Expectations." Journal of Finance, forthcoming.

Drechsel, Thomas. 2020. "Earning-Based Borrowing Constraints and Macroeconomic Fluctuations." Working paper, University of Maryland. 
Ericson, Richard, and Ariel Pakes. 1995. "Markov-Perfect Industry Dynamics: a Framework for Empirical Work." Review of Economic Studies, 62(1): 53-82.

Gopinath, Gita, Shebnem Kalemli-Ozcan, Loukas Karabarbounis and Carolina Villegas-Sanchez. 2017. "Capital Allocation and Productivity in South Europe." Quarterly Journal of Economics, 132(4): 1915-1967.

Griliches, Zvi, and Haim Regev. 1995. "Firm Productivity in Israeli Industry 1979-1989." Journal of Econometrics 65: 195-203.

Hart, Oliver, and John Moore. 1994. "A Theory of Debt Based on the Inalienability of Human Capital." Quarterly Journal of Economics 109(4): 841-879.

Hopenhayn, Hugo A. 1992. " Entry, Exit and Firm Dynamics in the Long Run." Econometrica, 60: 1127-1150.

Hoshi, Takeo, and Takatoshi Ito. 2020. Japanese Economy. Second Edition. Cambridge, MA: MIT Press.

Jorda, Oscar, Moritz Schularick, and Allan Taylor. 2018. "Macrofinancial History and the New Business Cycle Facts." NBER Macroeconomic Annual 2017, eds. by Martin Eichenbaum and Jonathan Parker. Chicago, IL: University of Chicago Press: 213-263.

Jovanovic, Boyan. 1982. "Selection and the Evolution of Industry." Econometrica, 50: 649-670.

Kiyotaki, Nobuhiro, and John Moore. 1997. "Credit Cycles." Journal of Political Economy, 105(2): 211-248.

Klette, Tor Jacob, and Samuel Kortum. 2004. "Innovating Firms and Aggregate Innovation." Journal of Political Economy 112(5): 986-1018.

Lian, Chen, and Yueran Ma. 2021. "Anatomy of Corporate Borrowing Constraints." Quarterly Journal of Economics 136(1): 229-291.

Reinhart, Carmen, and Kenneth Rogoff. 2009. This Time is Different. Princeton: Princeton University Press.

Reis, Ricardo. 2013. "The Portuguese Slump and Crash and the Euro Crisis," Brookings Papers on Economic Activity, 1 (2013), 143-210.

Rossi-Hansberg, Esteban, and Mark Wright. 2007. "Establishment Size Dynamics in the Aggregate Economy." American Economic Review 97(5): 1639-1699.

Schularick, Moritz, and Allan Taylor. 2012. "Credit Booms Gone Bust: Monetary Policy and Leverage Cycles, and Financial Crises, 1870-2008." American Economic Review : 1029-1061. 
Townsend, Robert. 1989. "Currency and Credit in a Private Information Economy." Journal of Political Economy, 97(6): 1323-1344. 


\section{Appendix}

\subsection{Appendix A}

In the main text, we assume that output is proportional to plant productivity. More generally, suppose that gross output $\widehat{y}$ depends upon plant productivity $\widehat{z}$ and unskilled labor $\widehat{h}$ as

$$
\widehat{y}=\widehat{a} \widehat{z}^{\alpha_{1}} \widehat{h}^{\alpha_{2}}, \text { where } \alpha_{1}+\alpha_{2} \leq 1 \text {. }
$$

Suppose there is a competitive labor market for unskilled workers at wage rate $\widehat{w}$. Then we can define the per-unit gross profit of a plant owner as

$$
\begin{aligned}
y & =\underset{\widehat{h}}{\operatorname{Max}}\left(\widehat{a} \widehat{z}^{\alpha_{1}} \widehat{h}^{\alpha_{2}}-\widehat{w} \widehat{h}\right) \\
& =a z
\end{aligned}
$$

where

$$
\begin{aligned}
z & =\widehat{z}^{\frac{\alpha_{1}}{1-\alpha_{2}}} \\
a & =\left(1-\alpha_{2}\right)\left(\frac{\alpha_{2}}{\widehat{w}}\right)^{\frac{\alpha_{2}}{1-\alpha_{2}}} \widehat{a} .
\end{aligned}
$$

If the supply of unskilled labor is perfectly elastic, we can treat $a$ as exogenous - this is the case of our model. (Otherwise, we need to take into account the general equilibrium effect on $a$ through $\widehat{w}$.)

If plant productivity depends upon initial plant productivity and human capital of engineer $h$ as

$$
\widehat{z}^{\prime}=\widehat{z}^{\theta} h^{\widehat{\eta}} \text {, where } \theta+\widehat{\eta} \leq 1 \text {. }
$$

we can rewrite this as

$$
z^{\prime}=z^{\theta} h^{\eta}, \text { where } \eta=\frac{\alpha_{1}}{1-\alpha_{2}} \widehat{\eta} .
$$

Thus we obtain the formulation in the text: $(31,32)$. 


\subsection{Appendix B}

\subsubsection{Individual Choice}

An individual agent takes wage, plant price and interest rate $\{w, b, R\}$ as given. An engineer chooses consumption, gross investment on tools and financial assets $\left(c, h^{\prime}, d^{\prime}\right)$ as a function of net worth $n$ to maximize $V^{E}(n ; w, b, R)$, $V^{E}(n ; w, b, R)=\underset{c, h^{\prime}, d^{\prime}}{\operatorname{ax}}\left\{\ln c+\beta\left[\pi^{E} V^{E}\left(n^{\prime} ; w, b, R\right)+\left(1-\pi^{E}\right) V^{S}\left(n^{\prime} ; w, b, R\right)\right]\right\}$,

subject to the budget constraint

$$
c+(x-b) h^{\prime}+\frac{d^{\prime}}{R}=n, \text { and } n^{\prime}=[w+\lambda(x-b)] h^{\prime}+d^{\prime} .
$$

Define the leveraged rate of return on investment as

$$
R^{E}=\frac{w+\lambda(x-b)}{x-b} .
$$

The first order conditions of the engineer's optimization problem are

$$
\begin{aligned}
& \frac{1}{c} \geq R^{E} \frac{\beta}{c^{\prime}}, \text { where }=\text { holds if } h^{\prime}>0, \\
& \frac{1}{c} \geq R \frac{\beta}{c^{\prime}}, \text { where }=\text { holds if } d^{\prime}>0 .
\end{aligned}
$$

Thus if $R^{E}>R$, we have $d^{\prime}=0,(10 a, 10 b)$ and

$$
n^{\prime}=R^{E} \beta n \text {. }
$$

A saver chooses consumption and financial assets $\left(c, d^{\prime}\right)$ as a function of net worth $n$ to maximize

$$
V^{S}(n ; w, b, R)=\underset{c, d^{\prime}}{\operatorname{aax}}\left\{\ln c+\beta\left[\pi^{S} V^{E}\left(n^{\prime} ; w, b, R\right)+\left(1-\pi^{S}\right) V^{S}\left(n^{\prime} ; w, b, R\right)\right]\right\}
$$

subject to the budget constraint

$$
c+\frac{d^{\prime}}{R}=n, \text { and } n^{\prime}=d^{\prime}
$$

Using the first order condition

$$
\frac{1}{c}=R \frac{\beta}{c^{\prime}},
$$


we get $(11 a, 11 b)$ and

$$
n^{\prime}=R \beta n \text {. }
$$

From these, we conjecture that the value functions of the engineer and the saver are given by

$$
\begin{aligned}
V^{E}(n ; w, b, R) & =\nu^{E}(w, b, R)+\frac{1}{1-\beta} \ln n, \\
V^{S}(n ; w, b, R) & =\nu^{S}(w, b, R)+\frac{1}{1-\beta} \ln n .
\end{aligned}
$$

From $(10 b, 34,11 b, 36)$, the conjecture is verified if and only if

$$
\begin{aligned}
\nu^{E}(w, b, R) & =\beta \pi^{E} \nu^{E}(w, b, R)+\beta\left(1-\pi^{E}\right) \nu^{S}(w, b, R)+\frac{\beta}{1-\beta} \ln R^{E}(w, b, R)+\ln (1-\beta), \\
\nu^{S}(w, b, R) & =\beta \pi^{S} \nu^{E}(w, b, R)+\beta\left(1-\pi^{S}\right) \nu^{S}(w, b, R)+\frac{\beta}{1-\beta} \ln R+\ln (1-\beta),
\end{aligned}
$$

when there is no change of $(w, b, R)$ in the future. Then we get

$$
\begin{gathered}
\nu^{E}(w, b, R)=\beta \frac{\left(1-\beta+\beta \pi^{S}\right) \ln \left(R^{E}(w, b, R)\right)+\beta\left(1-\pi^{E}\right) \ln R}{(1-\beta)^{2}\left(1+\beta \pi^{S}-\beta \pi^{E}\right)}+\frac{\ln (1-\beta)}{1-\beta}, \\
\nu^{S}(w, b, R)=\beta \frac{\beta \pi^{S} \ln \left(R^{E}(w, b, R)\right)+\left(1-\beta \pi^{E}\right) \ln R}{(1-\beta)^{2}\left(1+\beta \pi^{S}-\beta \pi^{E}\right)}+\frac{\ln (1-\beta)}{1-\beta} .
\end{gathered}
$$

The plant owner/saver's choice is given by the value function (5) in the main text. The first order condition for those who choose to continue operating the plant this period is

$$
\begin{aligned}
w & \geq \eta \frac{z^{\prime}}{h} \lambda V^{\prime}\left(z^{\prime} ; w, R\right), \text { where }=\text { holds if } h>0, \\
V^{\prime}(z ; w, R) & =\frac{1}{R}\left[a+\theta \frac{z^{\prime}}{z} \lambda V^{\prime}\left(z^{\prime} ; w, R\right)\right] .
\end{aligned}
$$

From these, if $h_{t}, h_{t+1}, \ldots>0$, we have

$$
\begin{aligned}
w= & \frac{\lambda}{R}\left[\eta \frac{z_{t+1}}{h_{t}} a+\eta \frac{z_{t+1}}{h_{t}} \theta \frac{z_{t+2}}{z_{t+1}} \lambda V^{\prime}\left(z_{t+2} ; w, R\right)\right] \\
= & \frac{\lambda}{R} a \eta \frac{z_{t+1}}{h_{t}}+\left(\frac{\lambda}{R}\right)^{2} a \eta \frac{z_{t+1}}{h_{t}} \theta \frac{z_{t+2}}{z_{t+1}}+\left(\frac{\lambda}{R}\right)^{3} a \eta \frac{z_{t+1}}{h_{t}} \theta \frac{z_{t+2}}{z_{t+1}} \theta \frac{z_{t+3}}{z_{t+2}} \\
& +\ldots
\end{aligned}
$$


This is (12) in the text. Multiplying through by $h_{t}$, and simplifying, we get (13) in the text. Then we get

$$
\begin{aligned}
& V(z ; w, R) \\
= & \frac{1}{R}\left(y_{t}-w h_{t}-f\right)+\frac{\lambda}{R^{2}}\left(y_{t+1}-w h_{t+1}-f\right)+\frac{\lambda^{2}}{R^{3}}\left(y_{t+2}-w h_{t+2}-f\right)+\ldots \\
= & \frac{1}{R}\left(y_{t}-f\right)+\frac{\lambda}{R^{2}}\left[y_{t+1}(1-\eta)-f\right]+\frac{\lambda^{2}}{R^{3}}\left[y_{t+2}(1-\eta-\eta \theta)-f\right]+\ldots
\end{aligned}
$$

This implies (14) in the text.

If $h_{t}, h_{t+1}>0$, we can use $(40,41)$ to derive an alternative first order condition as

$$
\begin{aligned}
w & =\frac{\lambda}{R} \eta \frac{z_{t+1}}{h_{t}} a+\frac{\lambda}{R} w \eta \frac{z_{t+1}}{h_{t}} \frac{\theta \frac{z_{t+2}}{z_{t+1}}}{\eta \frac{z_{t+2}}{h_{t+1}}} \\
& =\frac{\lambda}{R} \eta \frac{z_{t+1}}{h_{t}} a+\frac{\lambda}{R} \theta \frac{h_{t+1}}{h_{t}} w .
\end{aligned}
$$

Note that the second term on the right hand side equals the discounted wage rate times the marginal rate of substitution between $h_{t}$ and $h_{t+1}$ to keep $z_{t+2}$ constant. Thus equation (42) says the marginal cost of increasing $h_{t}$ by one unit equals the discounted value of marginal benefit - the sum of additional output through $z_{t+1}$ and saving of wage bill, keeping $z_{t+2}$ constant.

In the case of constant-returns-to-scale maintenance technology, $\theta+\eta=1$, we conjecture

$$
\begin{gathered}
S^{\infty}(z ; w, r)=a A^{\infty} z-\frac{f}{R-\lambda}, \\
S^{T}(z ; w, r)=a A^{T} z-\Lambda^{T} f, \text { where } \\
\Lambda^{T}=\frac{1}{R}+\frac{\lambda}{R^{2}}+\ldots+\frac{\lambda^{T-1}}{R^{T}}=\frac{1-\frac{\lambda^{T}}{R^{T}}}{R-\lambda} .
\end{gathered}
$$

For plant which continues forever, we conjecture and verify that

$$
\frac{h_{t+1}}{h_{t}}=\frac{z_{t+1}}{z_{t}}=\left(\frac{h_{t}}{z_{t}}\right)^{1-\theta}=g>1 .
$$

Then from (42), we get

$$
w=\frac{\frac{\lambda}{R} \eta \frac{z_{t+1}}{h_{t}} a}{1-\frac{\lambda}{R} \theta g}=\frac{\lambda(1-\theta) a}{R-\lambda \theta g} g^{-\frac{\theta}{1-\theta}}
$$


Then from (5), we learn that the Bellman equation for continuing plant holds if and only if

$$
A^{\infty}=\frac{1}{R-\lambda \theta g} .
$$

For stopping plant in finite time, (40) implies that

$$
w=(1-\theta)\left(\frac{z^{T}}{h^{T}}\right)^{\theta} \lambda a A^{T-1},
$$

where $z^{T}$ and $h^{T}$ are the productivity and tools of plant when it stops in $T$ periods. Then from (5), we learn that the Bellman equation for continuing plant holds if and only if

$$
\begin{aligned}
A^{T} & =\frac{1}{R}\left[1+\lambda \theta a A^{T-1}\left(\frac{1-\theta}{w} \lambda a A^{T-1}\right)^{\frac{1-\theta}{\theta}}\right] \\
& =\frac{1}{R}\left[1+\lambda \theta g(R-\lambda \theta g)^{\frac{1-\theta}{\theta}}\left(A^{T-1}\right)^{\frac{1}{\theta}}\right]
\end{aligned}
$$

using (44). Here $A^{1}$ is given by $A^{1}=\frac{1}{R}$.

When the maintenance technology is decreasing returns to scale, $\theta+\eta<$ 1 , we conjecture that the productivity of plant that continues forever will converge to a steady state productivity

$$
z=z^{*}
$$

Thus the amount of tools employed converges to

$$
h=h^{*}=\left(z^{*}\right)^{\frac{1-\theta}{\eta}} .
$$

We also conjecture that

$$
\begin{gathered}
S^{\infty}(z ; w, R)=a z^{*} U^{\infty}\left(\frac{z}{z^{*}} ; R\right)-\frac{f}{R-\lambda}, \\
S^{T}(z ; w, R)=a z^{*} U^{T}\left(\frac{z}{z^{*}} ; R\right)-\Lambda^{T} f .
\end{gathered}
$$

Using (42) for plant to continue forever in steady state, we get

$$
w=\frac{\lambda \eta a}{R-\lambda \theta}\left(z^{*}\right)^{-\frac{1-\eta-\theta}{\eta}}
$$


Define $\widetilde{z}=\frac{z}{z^{*}}$. Using the relationship $h=\left(\frac{z^{\prime}}{z^{\theta}}\right)^{\frac{1}{\eta}}$, we get

$$
\frac{w h}{a z^{*}}=\frac{\lambda \eta}{R-\lambda \theta}\left(\frac{\widetilde{z}^{\prime}}{\widetilde{z}^{\theta}}\right)^{\frac{1}{\eta}}
$$

Thus the guess is verified if $U^{\infty}(\widetilde{z})$ and $U^{T}(\widetilde{z})$ solve

$$
\begin{aligned}
& U^{\infty}(\widetilde{z} ; R)=\frac{1}{R} \operatorname{Max}_{\widetilde{z}^{\prime}}\left[\widetilde{z}-\frac{\lambda \eta}{R-\lambda \theta}\left(\frac{\widetilde{z}^{\prime}}{\widetilde{z}^{\theta}}\right)^{\frac{1}{\eta}}+\lambda U^{\infty}\left(\widetilde{z}^{\prime} ; R\right)\right], \\
& U^{T}(\widetilde{z} ; R)=\frac{1}{R} M_{\widetilde{z}^{\prime}} a x\left[\widetilde{z}-\frac{\lambda \eta}{R-\lambda \theta}\left(\frac{\widetilde{z}^{\prime}}{\widetilde{z}^{\theta}}\right)^{\frac{1}{\eta}}+\lambda U^{T-1}\left(\widetilde{z}^{\prime} ; R\right)\right],
\end{aligned}
$$

where $U^{1}(\widetilde{z} ; R)=\frac{1}{R} \widetilde{z}$.

\subsubsection{Market Clearing}

In order to describe the aggregate economy, let $K_{t}(\tau)$ be the aggregate number of age- $\tau$ plant which continues forever at date $t$. Suppose some owners choose to operate new plant for $T$ periods and then stop. Let $L_{t}^{T-\tau}(\tau)$ be aggregate number of age- $\tau$ plant which stops in $T-\tau$ periods at date $t$. Then we have the transition

$$
\begin{aligned}
K_{t}(\tau) & =\lambda K_{t-1}(\tau-1), \\
L_{t}^{T-\tau}(\tau) & =\lambda L_{t-1}^{T-\tau+1}(\tau-1), \text { for } \tau=1,2, \ldots, T-1
\end{aligned}
$$

We also have

$$
I_{t}=K_{t+1}(0)+L_{t+1}^{T}(0),
$$

where $I_{t}$ is aggregate investment at date t.

We also know that

$$
\begin{aligned}
& b=S^{\infty}(1 ; w, R)=S^{T}(1 ; w, R) \text { in M-Region, } \\
& b=S^{\infty}(1 ; w, R) \text { and } L_{t}^{T}(0)=0 \text { in P-Region. }
\end{aligned}
$$

Let $z_{t}^{T-\tau}(\tau)$ be the productivity of age- $\tau$ plant which stops in $T-\tau$ periods at date t. Let $h_{t}^{T-\tau}(\tau)$ be the number of tools employed by one unit of age- $\tau$ 
plant to stop in $T-\tau$ periods. Then the aggregate output and demand for tools (and engineers) are given by

$$
\begin{aligned}
Y_{t} & =\sum_{\tau=0}^{\infty}\left[a z_{t}^{\infty}(\tau)-f\right] K_{t}(\tau)+\sum_{\tau=0}^{T-1}\left[a z_{t}^{T-\tau}(\tau)-f\right] L_{t}^{T-\tau}(\tau), \\
H_{t} & =\sum_{\tau=0}^{\infty} h_{t}^{\infty}(\tau) K_{t}(\tau)+\sum_{\tau=0}^{T-1} h_{t}^{T-\tau}(\tau) L_{t}^{T-\tau}(\tau) .
\end{aligned}
$$

Aggregate domestic asset holding at the beginning of period $t$ equals the sum of gross profit and the value of plant from the last period minus net foreign debt:

$$
\begin{aligned}
D_{t}= & Y_{t}-w H_{t}-D_{t}^{*} \\
& +\sum_{\tau=1}^{\infty} V(z(\tau)) K_{t}(\tau)+\sum_{\tau=1}^{T} S^{T-\tau}\left(z_{t}^{T-\tau}(\tau)\right) L_{t}^{T-\tau}(\tau) .
\end{aligned}
$$

The goods market clearing condition is given by

$$
C_{t}+x I_{t}+D_{t}^{*}-\frac{D_{t+1}^{*}}{R}=Y_{t}
$$

Output equals consumption, investment and net export (which equals net debt repayment to foreigners). One of the market clearing conditions for output, tools and financial asset is not independent by Walras' Law.

\subsubsection{Pure Equilibrium with No Stopping}

When no plant owner stops his plant, the total number of continuing plant equals the total number of tools,

$$
\sum_{\tau=0}^{\infty} K_{t}(\tau)=H_{t}
$$

and the ratio of tools to plant remains at the initial ratio

$$
h_{t}^{\infty}(\tau)=1, \text { for all } \tau \text { and } t .
$$

The plant productivity remains at the initial level as

$$
z_{t}^{\infty}(\tau)=\left[z_{t-1}^{\infty}(\tau-1)\right]^{\theta}\left[h_{t-1}^{\infty}(\tau-1)\right]^{\eta}=1, \text { for all } \tau \text { and } t
$$


Thus the plant growth rate $g=1$ with constant-returns-to-scale maintenance technology, steady state productivity $z^{*}=1$ with decreasing-returns-to-scale maintenance technology, and

$$
\begin{aligned}
w & =\frac{\lambda \eta a}{R-\lambda \theta}=w(R), \\
b & =\frac{a-w-f}{R-\lambda}=\frac{1}{R-\lambda}\left[a \frac{R-\lambda(\theta+\eta)}{R-\lambda \theta}-f\right]=b(R) .
\end{aligned}
$$

In order to show that non-stopping is an optimal strategy for the plant owner, we need to check

$$
b(R)>\underset{T}{\operatorname{Max}} S^{T}(1 ; w(R), R)=\underset{T}{\operatorname{Max}}\left[a U^{T}(1 ; w(R), R)-\Lambda^{T} f\right],
$$

for any finite $T$, where $U^{T}(1 ; R)$ is given by (50) with decreasing returns to scale and equals $A^{T}$ with the constant returns to scale maintenance technology.

Then from $(54,56)$, we have

$$
\begin{aligned}
Y_{t} & =(a-f) H_{t}, \\
D_{t} & =(a-w-f) H_{t}+b \lambda H_{t}-D_{t}^{*} .
\end{aligned}
$$

We also have

$$
C_{t}=(1-\beta)\left[(w+\lambda(x-b)) H_{t}+D_{t}\right]
$$

From $(18 a, 57)$, we obtain the transitions:

$$
\begin{aligned}
(x-b) H_{t+1} & =\beta\left\{\pi^{E}(w+\lambda b) H_{t}+\pi^{S} D_{t}\right\} \\
\frac{D_{t+1}^{*}}{R} & =-(a-f) H_{t}+C_{t}+x\left(H_{t+1}-\lambda H_{t}\right)+D_{t}^{*} .
\end{aligned}
$$

$(w, b)$ is a function of $R$ and the other parameters, and $\left(D_{t}, C_{t}\right)$ is a function of $\left(H_{t}, D_{t}^{*}\right)$ and $R$ (through $w$ and $b$ ). Then, the perfect foresight equilibrium (aside from a unanticipated permanent shock on $R$ ) is characterized recursively by $\left(H_{t+1}, D_{t+1}^{*}\right)$ as a function of $\left(H_{t}, D_{t}^{*}, R\right)$.

In steady state, we can use (19) to find steady-state growth rate where

$$
R^{E}=\frac{w(R)+\lambda[x-b(R)]}{x-b(R)} .
$$




\subsubsection{Mixed Equilibrium}

For the mixed equilibrium, we only describe the steady state equilibrium.

Mixed equilibrium under constant returns to scale maintenance technology From $(44,45)$, we have

$$
\begin{aligned}
w & =\frac{\lambda(1-\theta) a}{R-\lambda \theta g} g^{-\frac{\theta}{1-\theta}}=w(g ; R) \\
b & =\frac{a}{R-\lambda \theta g}-\frac{f}{R-\lambda}=b(g ; R) .
\end{aligned}
$$

Find $\left\{A^{1}, A^{2}, A^{3}, \ldots, A^{T}\right\}$ to solve (47) with $A^{1}=\frac{1}{R}$ as a function of $(g ; R)$. Find $g$ to solve the indifference condition:

$$
b(g ; R)=\underset{\text { finite } T}{\operatorname{Max}}\left[a A^{T}(g ; R)-\Lambda^{T} f\right] .
$$

Equilibrium stopping time is $\arg \operatorname{Max}\left[a A^{T}(g ; R)-\Lambda^{T} f\right]$ for this equilibrium $g$.

Then we can find the steady state growth rate from (19) by using

$$
R^{E}=\frac{w(g ; R)+\lambda[x-b(g ; R)]}{x-b(g ; R)} .
$$

For plant that continues forever, because $z^{\infty}(0)=1$, we get $z^{\infty}(\tau)=g^{\tau}$ and

$$
h^{\infty}(\tau)=\left[\frac{z^{\infty}(\tau+1)}{\left(z^{\infty}(\tau)\right)^{\theta}}\right]^{\frac{1}{1-\theta}}=g^{\frac{1}{1-\theta}+\tau} .
$$

For those stopping in $T$ periods, we get from the first order condition (46)

$$
\frac{h^{T-\tau}(\tau)}{z^{T-\tau}(\tau)}=\left[\frac{(1-\theta) \lambda}{w / a} A^{T-\tau-1}\right]^{\frac{1}{\theta}}=\left(\frac{A^{T-\tau-1}}{A^{\infty}}\right)^{\frac{1}{\theta}} g^{\frac{1}{1-\theta}}
$$

for $\tau=0,1,2, \ldots, T-2$. Because $z^{T}(0)=1$, we obtain $\left\{h^{T-\tau}(\tau), z^{T-\tau-1}(\tau+1)\right\}$ which satisfies (64) and

$$
z^{T-\tau-1}(\tau+1)=\left(\frac{A^{T-\tau-1}}{A^{\infty}}\right)^{\frac{1-\theta}{\theta}} g z^{T-\tau}(\tau),
$$

for $\tau=0,1,2, \ldots, T-2$. 
Mixed equilibrium under decreasing returns to scale maintenance technology With decreasing returns, from (48), we get

$$
w=\frac{\lambda \eta a}{R-\lambda \theta}\left(z^{*}\right)^{-\frac{1-\theta-\eta}{\eta}}=w\left(z^{*} ; R\right) .
$$

For plant to continue for ever, we have from (49):

$$
\begin{aligned}
U^{\infty}(\widetilde{z}) & =\frac{1}{R} M_{\widetilde{z}^{\prime}} x\left[\widetilde{z}-\frac{\lambda \eta}{R-\lambda \theta}\left(\frac{\widetilde{z}^{\prime}}{\widetilde{z}^{\theta}}\right)^{\frac{1}{\eta}}+\lambda U^{\infty}\left(\widetilde{z}^{\prime}\right)\right] \\
\widetilde{z}^{\prime} & =\arg M_{\widetilde{z}^{\prime}} a x\left[\widetilde{z}-\frac{\lambda \eta}{R-\lambda \theta}\left(\frac{\widetilde{z}^{\prime}}{\widetilde{z}^{\theta}}\right)^{\frac{1}{\eta}}+\lambda U^{\infty}\left(\widetilde{z}^{\prime}\right)\right] \equiv \varphi^{\infty}(\widetilde{z})
\end{aligned}
$$

Let $\widetilde{z}^{\infty}(\tau)$ and $\widetilde{h}^{\infty}(\tau)$ be productivity and number of tools of age- $\tau$ plant which continues forever relative to the steady state. The we have

$$
\begin{aligned}
& \widetilde{z}^{\infty}(\tau)=\left(\varphi^{\infty}\right)^{\tau}\left(\widetilde{z}^{\infty}(0)\right)=\left(\varphi^{\infty}\right)^{\tau}\left(\frac{1}{z^{*}}\right) \\
& \widetilde{h}^{\infty}(\tau)=\left[\frac{\widetilde{z}^{\infty}(\tau+1)}{\left(\widetilde{z}^{\infty}(\tau)\right)^{\theta}}\right]^{\frac{1}{\eta}} .
\end{aligned}
$$

For plant to stop in $T$ periods, we have from (50):

$$
\begin{aligned}
U^{T}(\widetilde{z}) & =\frac{1}{R} M_{\widetilde{z}^{\prime}}\left[\widetilde{z}-\frac{\lambda \eta}{R-\lambda \theta}\left(\frac{\widetilde{z}^{\prime}}{\widetilde{z}^{\theta}}\right)^{\frac{1}{\eta}}+\lambda U^{T-1}\left(\widetilde{z}^{\prime}\right)\right] \\
\widetilde{z}^{\prime} & =\arg M_{\widetilde{z}^{\prime}}\left[\widetilde{z}-\frac{\lambda \eta}{R-\lambda \theta}\left(\frac{\widetilde{z}^{\prime}}{\widetilde{z}^{\theta}}\right)^{\frac{1}{\eta}}+\lambda U^{T-1}\left(\widetilde{z}^{\prime}\right)\right] \equiv \varphi^{T}(\widetilde{z}),
\end{aligned}
$$

where $U^{1}(\widetilde{z})=\frac{1}{R} \widetilde{z}$. Let $\widetilde{z}^{T-\tau}(\tau)$ and $\widetilde{h}^{T-\tau}(\tau)$ be productivity and tools of age- $\tau$ plant which stops in $T-\tau$ periods relative to the steady state. Then we have

$$
\begin{aligned}
& \widetilde{z}^{T-\tau}(\tau)=\varphi^{T} \cdot \varphi^{T-1} \cdot \ldots \cdot \varphi^{T-\tau+1}\left(\frac{1}{z^{*}}\right) \\
& \widetilde{h}^{T-\tau}(\tau)=\left[\frac{\widetilde{z}^{T-\tau-1}(\tau+1)}{\left(\widetilde{z}^{T-\tau}(\tau)\right)^{\theta}}\right]^{\frac{1}{\eta}} .
\end{aligned}
$$


We then find $z^{*}$ to satisfy the indifference condition

$$
\begin{aligned}
a z^{*} U^{\infty}\left(\frac{1}{z^{*}}\right)-\frac{f}{R-\lambda} & =\underset{\text { finite } T}{\operatorname{Max}}\left[a z^{*} U^{T}\left(\frac{1}{z^{*}}\right)-\Lambda^{T} f\right] \\
& =b\left(z^{*} ; R\right)
\end{aligned}
$$

This common value under equilibrium $z^{*}$ is the engineer's borrowing capacity. Equilibrium stopping time equals arg $\operatorname{Max}\left[a z^{*} U^{T}\left(\frac{1}{z^{*}}\right)-\Lambda^{T} f\right]$.

We can find the steady state growth rate from (19) with

$$
R^{E}=\frac{w\left(z^{*} ; R\right)+\lambda\left[x-b\left(z^{*} ; R\right)\right]}{x-b\left(z^{*} ; R\right)}=R^{E}\left(z^{*} ; R\right) .
$$

\subsubsection{Tools and goods market clearing in mixed equilibrium}

In the steady state, we observe

$$
G=\frac{H_{t+1}}{H_{t}}=\frac{K_{t+1}(\tau)}{K_{t}(\tau)}=\frac{L_{t+1}^{T-\tau}(\tau)}{L_{t}^{T-\tau}(\tau)} .
$$

For both constant and decreasing returns-to-scale maintenance technology, we have aggregate output under mixed equilibrium as (54). Using (51), we obtain

$$
Y_{t}=\sum_{\tau=0}^{\infty}\left[a z^{\infty}(\tau)-f\right] \frac{\lambda^{\tau}}{G^{\tau}} K_{t}(0)+\sum_{\tau=0}^{T-1}\left[a z^{T-\tau}(\tau)-f\right] \frac{\lambda^{\tau}}{G^{\tau}} L_{t}^{T}(0) .
$$

Similarly, aggregate demand for tools (55) becomes

$$
H_{t}=\sum_{\tau=0}^{\infty} h^{\infty}(\tau) \frac{\lambda^{\tau}}{G^{\tau}} K_{t}(0)+\sum_{\tau=0}^{T-1} h^{T-\tau}(\tau) \frac{\lambda^{\tau}}{G^{\tau}} L_{t}^{T}(0) .
$$

Because $I_{t}=(G-\lambda) H_{t}=K_{t+1}(0)+L_{t+1}^{T}(0)$, dividing (66) by $H_{t}$, we find in the steady state:

$$
1=\sum_{\tau=0}^{\infty} h^{\infty}(\tau) \frac{\lambda^{\tau}}{G^{\tau+1}}(G-\lambda) i^{k}+\sum_{\tau=0}^{T-1} h^{T-\tau}(\tau) \frac{\lambda^{\tau}}{G^{\tau+1}}(G-\lambda)\left(1-i^{k}\right)
$$


where $i^{k} \equiv \frac{K_{t+1}(0)}{I_{t}} \in(0,1)$. We can solve for $i^{k} \in(0,1)$ to satisfy $(67)$. Similarly, output per tool is

$$
\frac{Y_{t}}{H_{t}}=\sum_{\tau=0}^{\infty}\left[a z^{\infty}(\tau)-f\right] \frac{\lambda^{\tau}}{G^{\tau+1}}(G-\lambda) i^{k}+\sum_{\tau=0}^{T-1}\left[a z^{T-\tau}(\tau)-f\right] \frac{\lambda^{\tau}}{G^{\tau+1}}(G-\lambda)\left(1-i^{k}\right) .
$$

Aggregate domestic financial asset holding (56) under constant-returnsto-scale maintenance technology is given by

$$
\begin{aligned}
& D_{t}=Y_{t}-w H_{t}-D_{t}^{*} \\
& +\sum_{\tau=1}^{\infty}\left(\frac{a}{R-\lambda \theta g}-\frac{f}{R-\lambda}\right) \frac{\lambda^{\tau}}{G^{\tau}} K_{t}(0)+\sum_{\tau=1}^{T-1}\left(a A^{T-\tau} z^{T-\tau}(\tau)-\Lambda^{T} f\right) \frac{\lambda^{\tau}}{G^{\tau}} L_{t}^{T}(0), \\
& \text { or } \frac{D_{t}}{H_{t}}=\frac{Y_{t}}{H_{t}}-w-d_{t}^{*} \\
& +\sum_{\tau=1}^{\infty}\left(\frac{a}{R-\lambda \theta g}-\frac{f}{R-\lambda}\right) \frac{\lambda^{\tau}}{G^{\tau+1}}(G-\lambda) i^{k}+\sum_{\tau=1}^{T-1}\left(a A^{T-\tau} z^{T-\tau}(\tau)-\Lambda^{T} f\right) \frac{\lambda^{\tau}}{G^{\tau+1}}(G-\lambda)\left(1-i^{k}\right), \\
& \text { where } d_{t}^{*}=D_{t}^{*} / H_{t} . \\
& \text { Similarly, domestic financial asset holding per tool under decreasing re- } \\
& \frac{D_{t}}{H_{t}}=\frac{Y_{t}}{H_{t}}-w-d_{t}^{*} \\
& +\sum_{\tau=1}^{\infty}\left(a z^{*} U\left(\widetilde{z}^{\infty}(\tau)\right)-\frac{f}{R-\lambda}\right) \frac{\lambda^{\tau}}{G^{\tau+1}}(G-\lambda) i^{k}+\sum_{\tau=1}^{T}\left(a z^{*} U\left(\widetilde{z}^{T-\tau}(\tau)\right)-\Lambda^{T} f\right) \frac{\lambda^{\tau}}{G^{\tau+1}}(G-\lambda)\left(1-i^{k}\right) .
\end{aligned}
$$

We also find

$$
\frac{C_{t}}{H_{t}}=(1-\beta)\left[w+\lambda(x-b)+\frac{D_{t}}{H_{t}}\right] .
$$

From (57), in steady state,

$$
\frac{Y_{t}}{H_{t}}=\frac{C_{t}}{H_{t}}+G-\lambda+d^{*}-\frac{G}{R} d^{*}
$$

or

$$
\left(1-\frac{G}{R}\right) d^{*}=\frac{Y_{t}}{H_{t}}-\frac{C_{t}}{H_{t}}-(G-\lambda)
$$

From this, we find the ratio of net foreign debt to tools in steady state. 


\subsection{Proof of Proposition 2}

We first derive a sufficient condition for the existence of a pure non-stopping equilibrium in P-region:

$$
\begin{aligned}
V(1) & =\frac{1}{R-\lambda}\left(a \frac{R-(\theta+\eta) \lambda}{R-\theta \lambda}-f\right) \\
& \geq \frac{a}{R}\left(1-\frac{\theta \lambda}{R}\right)^{\frac{\eta}{1-\theta-\eta}} \frac{1-\theta-\eta}{1-\theta}+\frac{a \eta}{(1-\theta)(R-\theta \lambda)}-\frac{f}{R}
\end{aligned}
$$

We consider a sufficient condition of (59)

$$
b(R)>\underset{T}{\operatorname{Max}} S^{T}(1 ; w(R), R),
$$

for the case of decreasing-returns-to-scale maintenance technology. Consider an optimal stopping strategy in the RHS as

$$
\left\{z^{T}(0)>z^{T-1}(1)>\ldots>z^{0}(T)\right\}=\left\{z_{0}>z_{1}>\ldots>z_{T}\right\}
$$

such that $z_{0}=1$ and $z_{T} \geq \underline{z}=f / a$. Associated with $\left\{z_{t}\right\}$, there is $h_{t}=$ $\left(\frac{z_{t+1}}{z_{t}^{\theta}}\right)^{1 / \eta}$. Let $v(h \mid z)$ denote the flow payoff of the owner of a unit of plant with productivity $z$ who hires $h$ units of tools.

$$
v(h \mid z)=a z-w h-f .
$$

Because optimal stopping strategy $z_{t}>z_{t+1}$ is better than staying at $z_{t}$ with $h=z_{t}^{\frac{1-\theta}{\eta}}$, we get

$$
\begin{aligned}
v\left(h_{t} \mid z_{t}\right)+\lambda V\left(z_{t+1}\right) & \geq v\left(z_{t}^{\frac{1-\theta}{\eta}} \mid z_{t}\right)+\lambda V\left(z_{t}\right), \text { or } \\
V\left(z_{t}\right)-V\left(z_{t+1}\right) & \leq \frac{1}{\lambda}\left[v\left(h_{t} \mid z_{t}\right)-v\left(z_{t}^{\frac{1-\theta}{\eta}} \mid z_{t}\right)\right] .
\end{aligned}
$$

Let $\phi\left(z \mid z_{t}\right) \equiv v\left(\left(z / z_{t}^{\theta}\right)^{\frac{1}{\eta}} \mid z_{t}\right)=a z_{t}-w\left(z / z_{t}^{\theta}\right)^{\frac{1}{\eta}}-f$.

$$
v\left(h_{t} \mid z_{t}\right)-v\left(z_{t}^{\frac{1-\theta}{\eta}} \mid z_{t}\right)=\int_{z_{t+1}}^{z_{t}}-\phi^{\prime}\left(z \mid z_{t}\right) d z
$$


where

$$
-\phi^{\prime}\left(z \mid z_{t}\right)=\frac{w}{\eta} \frac{z^{\frac{1}{\eta}-1}}{z_{t}^{\frac{\theta}{\eta}}}
$$

Notice that because

$$
\frac{\partial}{\partial z_{t}}\left[-\phi^{\prime}\left(z \mid z_{t}\right)\right]<0
$$

we have

$$
-\phi^{\prime}\left(z \mid z_{t}\right)=\frac{w}{\eta} \frac{z^{\frac{1}{\eta}-1}}{z_{t}^{\frac{\theta}{\eta}}} \leq \frac{w}{\eta} z^{\frac{1-\theta}{\eta}-1}=-\phi^{\prime}(z \mid z), \text { for } z_{t+1} \leq z \leq z_{t} .
$$

Then,

$$
v\left(h_{t} \mid z_{t}\right)-v\left(z_{t}^{\frac{1-\theta}{\eta}} \mid z_{t}\right)=\int_{z_{t+1}}^{z_{t}}-\phi^{\prime}\left(z \mid z_{t}\right) d z \leq \int_{z_{t+1}}^{z_{t}}-\phi^{\prime}(z \mid z) d z .
$$

Combining this inequality with inequality (71), we have

$$
\begin{gathered}
V\left(z_{t}\right)-V\left(z_{t+1}\right) \leq \frac{1}{\lambda}\left[v\left(h_{t} \mid z_{t}\right)-v\left(z_{t}^{\frac{1-\theta}{\eta}} \mid z_{t}\right)\right] \leq \frac{1}{\lambda} \int_{z_{t+1}}^{z_{t}} \frac{w}{\eta} z^{\frac{1-\theta}{\eta}-1} d z, \\
V(1)-V\left(z_{T}\right)=\sum_{t=0}^{T-1}\left[V\left(z_{t}\right)-V\left(z_{t+1}\right)\right] \leq \frac{1}{\lambda} \int_{z_{T}}^{1} \frac{w}{\eta} z^{\frac{1-\theta}{\eta}-1} d z
\end{gathered}
$$

where we use $z_{1}=1$ in the last inequality. Because

$$
V\left(z_{T}\right)=\frac{1}{R}\left(a z_{T}-f\right)
$$

and

$$
\frac{1}{\lambda} \int_{z_{T}}^{1} \frac{w}{\eta} z^{\frac{1-\theta}{\eta}-1} d z=\frac{w}{\lambda(1-\theta)}\left(1-z_{T}^{\frac{1-\theta}{\eta}}\right)
$$

we have

$$
V(1) \leq \frac{1}{R}\left(a z_{T}-f\right)+\frac{w}{\lambda(1-\theta)}\left(1-z_{T}^{\frac{1-\theta}{\eta}}\right) \equiv R H S\left(z_{T}\right),
$$

if we are not in region $P$, i.e., some plant owners stop their plant. 
To derive a sufficient condition for Region $P$, we use the fact that equilibrium wage in this region satisfies

$$
\frac{w}{a}=\frac{\lambda \eta}{R-\theta \lambda} .
$$

Then RHS of (72) reaches the maximum when

$$
\begin{aligned}
z_{T} & =\left(1-\frac{\theta \lambda}{R}\right)^{\frac{\eta}{1-\theta-\eta}} \\
R H S & =\frac{a}{R}\left(1-\frac{\theta \lambda}{R}\right)^{\frac{\eta}{1-\theta-\eta}} \frac{1-\theta-\eta}{1-\theta}+\frac{a \eta}{(1-\theta)(R-\theta \lambda)}-\frac{f}{R} .
\end{aligned}
$$

A sufficient condition for the economy to be in Region $P$ is

$$
\begin{aligned}
V(1) & =\frac{1}{R-\lambda}\left(a \frac{R-(\theta+\eta) \lambda}{R-\theta \lambda}-f\right) \\
& \geq \frac{a}{R}\left(1-\frac{\theta \lambda}{R}\right)^{\frac{\eta}{1-\theta-\eta}} \frac{1-\theta-\eta}{1-\theta}+\frac{a \eta}{(1-\theta)(R-\theta \lambda)}-\frac{f}{R} .
\end{aligned}
$$

This yields an upper bound on $f / a$ :

$$
\frac{f}{a} \leq \frac{R(1-\theta-\eta)}{\lambda(1-\theta)}\left[1-\frac{R-\lambda}{R}\left(1-\frac{\theta \lambda}{R}\right)^{\frac{\eta}{1-\theta-\eta}}\right] \equiv \bar{\digamma}(f / a) .
$$

$\bar{\digamma}(f / a)$ denotes an upper bound for $f / a$ as a sufficient condition for the existence of a pure equilibrium with no stopping.

Now we proceed to derive a lower bound on $f / a$ such that the growth rate is an increasing function of real interest rate in state equilibrium. From (19), we learn

$$
\begin{aligned}
0 & =\left(G-\pi^{E} \beta R^{E}\right)\left[G-\left(1-\pi^{S}\right) \beta R\right]-\pi^{S}\left(1-\pi^{E}\right) \beta^{2} R R^{E} \\
& =\left[G-\pi^{E} \beta\left(\lambda+\frac{w}{x-b}\right)\right]\left[G-\left(1-\pi^{S}\right) \beta R\right]-\pi^{S}\left(1-\pi^{E}\right) \beta^{2} R\left(\lambda+\frac{w}{x-b}\right) \\
& \equiv \Psi\left(G ; R, \frac{w}{x-b}\right) .
\end{aligned}
$$

Because we assume $\beta R<1$, we restrict our attention the case

$$
G>\left(1-\pi^{S}\right) \beta R .
$$


Then we learn

$$
G \geq \pi^{E} \beta\left(\lambda+\frac{w}{x-b}\right)
$$

Then we learn

$$
\frac{\partial}{\partial G} \Psi\left(G ; R, \frac{w}{x-b}\right)>0,
$$

in the neighborhood of the equilibrium $G$. We can easily check

$$
\begin{gathered}
\frac{\partial}{\partial R} \Psi\left(G ; R, \frac{w}{x-b}\right)<0, \\
\frac{\partial}{\partial\left(\frac{w}{x-b}\right)} \Psi\left(G ; R, \frac{w}{x-b}\right)<0 .
\end{gathered}
$$

Thus a sufficient condition for

$$
\frac{d G}{d R}=-\frac{\frac{\partial}{\partial G} \Psi\left(G ; R, \frac{w}{x-b}\right)}{\frac{\partial}{\partial R} \Psi\left(G ; R, \frac{w}{x-b}\right)+\frac{\partial}{\partial\left(\frac{w}{x-b}\right)} \Psi\left(G ; R, \frac{w}{x-b}\right) \frac{d}{d R}\left(\frac{w}{x-b}\right)}>0
$$

is

$$
\begin{aligned}
0 & <\frac{d}{d R}\left(\frac{w}{x-b}\right) \\
& =\frac{w}{(x-b)^{2}(R-\lambda)^{2}(R-\lambda \theta)}\left[\lambda(1-\theta) f-(R-\lambda)^{2} x-\lambda(1-\theta-\eta) a\right],
\end{aligned}
$$

or

$$
\lambda(1-\theta) f>(R-\lambda)^{2} x+\lambda(1-\theta-\eta) a .
$$

If $\pi^{S}=0$, then from (19), we have $G=\pi^{E} \beta\left(\lambda+\frac{w}{x-b}\right)$, or

$$
\begin{aligned}
x & =F(R, G)=\frac{a-f-w}{R-\lambda}+\frac{\beta \pi^{E}}{G-\beta \lambda \pi^{E}} w \\
& =\frac{a-f}{R-\lambda}-\frac{G-\beta R \pi^{E}}{(R-\lambda)\left(G-\beta \lambda \pi^{E}\right)} w .
\end{aligned}
$$

Because $F_{G}<0, d G / d R>0$ if and only if $F_{R}>0$. And because

$$
(R-\lambda) F_{R}=-\frac{a-f-w}{R-\lambda}+\frac{G-\beta R \pi^{E}}{G-\beta \lambda \pi^{E}} \frac{a \eta \lambda}{(R-\theta \lambda)^{2}},
$$


$d G / d R>0$ iff

$$
f / a>\frac{R-(\theta+\eta) \lambda}{R-\theta \lambda}-\frac{G-\beta R \pi^{E}}{G-\beta \lambda \pi^{E}} \frac{\eta \lambda(R-\lambda)}{(R-\theta \lambda)^{2}} \equiv \underline{\digamma}(f / a)
$$

when $\pi^{S}=0$. For the growth-enhancing effect of interest rate in Region $P$, we need

$$
\bar{\digamma}(f / a)-\underline{\digamma}(f / a)>0
$$

or

$$
\begin{aligned}
\frac{\bar{\digamma}(f / a)-\underline{\digamma}(f / a)}{R-\lambda} & =\frac{R(1-\theta-\eta)-\lambda(1-\theta)(\theta+\eta)}{\lambda(1-\theta)(R-\theta \lambda)} \\
& -\frac{1-\theta-\eta}{\lambda(1-\theta)}\left(1-\frac{\theta \lambda}{R}\right)^{\frac{\eta}{1-\theta-\eta}}+\frac{G-\beta R \pi^{E}}{G-\beta \lambda \pi^{E}} \frac{\eta \lambda}{(R-\theta \lambda)^{2}}>0
\end{aligned}
$$

Suppose both $R$ and $\lambda$ are close to 1 ,

$$
\begin{aligned}
\frac{\bar{\digamma}(f / a)-\underline{\boldsymbol{F}}(f / a)}{R-\lambda} & \approx \frac{1-\theta-\eta-(1-\theta)(\theta+\eta)}{(1-\theta)^{2}}-\frac{1-\theta-\eta}{(1-\theta)}(1-\theta)^{\frac{\eta}{1-\theta-\eta}}+\frac{\eta}{(1-\theta)^{2}} \\
& =\frac{1-\theta-\eta}{1-\theta}\left[1-(1-\theta)^{\frac{\eta}{1-\theta-\eta}}\right] \\
& >0 .
\end{aligned}
$$

This proves that for any $f / a$, there exists an open set of interest rates and depreciation rates, both of which are close to 1 , where we have the property that the growth rate is an increasing function of the interest rate in Region $P$.

To examine the effect of an unanticipated fall in real interest rate on welfare in the pure non-stopping region, we use $(37 a, 37 b, 38,39)$. Continue to assume $\pi^{S}=0$. Then we have

$$
\begin{aligned}
\frac{d V^{E}}{d R}= & \frac{1}{1-\beta} \frac{d}{d R}\left(\ln n^{E}\right) \\
& +\frac{\beta}{(1-\beta)\left(1-\beta \pi^{E}\right)} \frac{d}{d R}\left[\ln \left(\frac{w+\lambda(x-b)}{x-b}\right)\right] \\
& +\frac{\beta^{2}\left(1-\pi^{E}\right)}{(1-\beta)^{2}\left(1-\beta \pi^{E}\right)} \frac{d}{d R} \ln R .
\end{aligned}
$$


From $(58 a, 58 b)$, we have

$$
\begin{aligned}
\frac{d w}{d R} & =-\frac{w}{R-\lambda \theta} \\
\frac{d b}{d R} & =\frac{1}{R-\lambda}\left(\frac{w}{R-\lambda \theta}-b\right) .
\end{aligned}
$$

Then we get

$$
\begin{aligned}
\frac{d}{d R} \ln [w+\lambda(x-b)]= & \frac{1}{w+\lambda(x-b)} \frac{1}{(R-\lambda)^{2}}\left(a-f-\frac{R^{2}-\lambda^{2} \theta}{(R-\lambda \theta)^{2}} \eta a\right), \\
\frac{d}{d R} \ln \left(\lambda+\frac{w}{x-b}\right)= & \frac{w}{[w+\lambda(x-b)](x-b)(R-\lambda)^{2}(R-\lambda \theta)^{2}} \\
& \cdot\left[\lambda \eta a-\lambda(1-\theta)(a-f)-(R-\lambda)^{2} x\right] .
\end{aligned}
$$

When $\pi^{S}=0, n^{E}=[w+\lambda(x-b)] h$. Then from (75), we have

$$
\begin{aligned}
& (1-\beta)\left(1-\beta \pi^{E}\right)(R-\lambda)^{2}(R-\lambda \theta)^{2}[w+\lambda(x-b)] \frac{d V^{E}}{d R} / \lambda \\
= & \left(1-\beta \pi^{E}\right)\left[(R-\lambda \theta)^{2}(a-f)-\left(R^{2}-\lambda^{2} \theta\right) \eta a\right] \\
+ & \frac{\beta a \eta}{x-b}\left[\lambda \eta a-\lambda(1-\theta)(a-f)-(R-\lambda)^{2} x\right] \\
& +\frac{\beta^{2}\left(1-\pi^{E}\right)}{1-\beta} \frac{(R-\lambda)(R-\lambda \theta)}{R}\{(R-\lambda \theta)[(R-\lambda) x-(a-f)]+R \eta a\} .
\end{aligned}
$$

\subsection{Welfare effect of policy}

From $(37 a, 37 b, 38,39)$, we learn that the welfare of a continuing engineer, retiring engineer, new engineer, and continuing saver are

$$
\begin{aligned}
V^{E E} & =\beta \frac{\left(1-\beta+\beta \pi^{S}\right) \ln R^{E}+\beta\left(1-\pi^{E}\right) \ln R}{(1-\beta)^{2}\left(1+\beta \pi^{S}-\beta \pi^{E}\right)}+\frac{\ln [w+\lambda(x-b-s)]}{1-\beta} h+\text { constant, } \\
V^{E S} & =\beta \frac{\beta \pi^{S} \ln R^{E}+\left(1-\beta \pi^{E}\right) \ln R}{(1-\beta)^{2}\left(1+\beta \pi^{S}-\beta \pi^{E}\right)}+\frac{\ln [w+\lambda(x-b-s)]}{1-\beta} h+\text { constant, } \\
V^{S E} & =\beta \frac{\left(1-\beta+\beta \pi^{S}\right) \ln R^{E}+\beta\left(1-\pi^{E}\right) \ln R}{(1-\beta)^{2}\left(1+\beta \pi^{S}-\beta \pi^{E}\right)}+\frac{\ln d}{1-\beta}+\text { constant, } \\
V^{S S} & =\beta \frac{\beta \pi^{S} \ln R^{E}+\left(1-\beta \pi^{E}\right) \ln R}{(1-\beta)^{2}\left(1+\beta \pi^{S}-\beta \pi^{E}\right)}+\frac{\ln d}{1-\beta}+\text { constant, }
\end{aligned}
$$


where $h$ is the number of tools and $d$ is financial asset held from the last period. Notice that government tax-subsidy does not affect the value of plant $b$ and thus it does not affect $d$. From $(23,24,26)$, we see that in the neighborhood of $\tau=0$,

$$
\begin{gathered}
\frac{\partial}{\partial \tau} \ln R^{E}=\frac{w}{[w+\lambda(x-b)](G-\lambda)}\left(R^{E}-G\right), \\
\frac{\partial}{\partial \tau} \ln [w+\lambda(x-b-s)]=-\frac{w}{[w+\lambda(x-b)](G-\lambda)} G .
\end{gathered}
$$

In steady state, we learn that the fractions of population of engineers and savers, $\left(m_{E}, m_{S}\right)$, satisfy

$$
\pi^{S} m_{S}=\left(1-\pi^{E}\right) m_{E}
$$

where the LHS is the flow of savers to become engineers and the RHS is the flow of retiring engineers. Thus

$$
m_{E}=\frac{\pi^{S}}{\pi^{S}+1-\pi^{E}}, \text { and } m_{S}=\frac{1-\pi^{E}}{\pi^{S}+1-\pi^{E}} .
$$

We consider a welfare measure as the population-weighted average of the welfare of each type of agents:

$$
V=m_{E}\left[\pi^{E} V^{E E}+\left(1-\pi^{E}\right) V^{E S}\right]+m_{S}\left[\pi^{S} V^{E E}+\left(1-\pi^{S}\right) V^{S S}\right] .
$$

Using the above expressions, we learn

$$
\begin{aligned}
V & =\frac{\pi^{S} \nu^{E}+\left(1-\pi^{E}\right) \nu^{E}}{\pi^{S}+1-\pi^{E}}+\frac{\pi^{S} \ln [w+\lambda(x-b)]}{\pi^{S}+1-\pi^{E}}+\text { constant } \\
& =\frac{\pi^{S}}{\left(\pi^{S}+1-\pi^{E}\right)(1-\beta)^{2}}\left\{\beta \ln R^{E}+(1-\beta) \ln [w+\lambda(x-b)]\right\}+\text { constant. }
\end{aligned}
$$

Therefore the effect of a tax and subsidy on the social welfare is

$$
\begin{aligned}
\frac{\partial V}{\partial \tau} & =\frac{\pi^{S}}{\left(\pi^{S}+1-\pi^{E}\right)(1-\beta)^{2}} \frac{w}{[w+\lambda(x-b)](G-\lambda)}\left[\beta\left(R^{E}-G\right)-(1-\beta) G\right] \\
& =\frac{\pi^{S}}{\left(\pi^{S}+1-\pi^{E}\right)(1-\beta)^{2}} \frac{w}{[w+\lambda(x-b)](G-\lambda)}\left(\beta R^{E}-G\right) \\
& >0 .
\end{aligned}
$$


The last inequality is obtained because the growth rate of economy is the weighted average of growth rate of engineers $\beta R^{E}$ and savers $\beta R$ and $R^{E}>R$ in our economy.

Individually, if $\pi^{S}$ is close to zero, we learn

$$
\frac{\partial V^{E E}}{\partial \tau}>0, \frac{\partial V^{E S}}{\partial \tau}<0, \frac{\partial V^{S E}}{\partial \tau}>0, \frac{\partial V^{S S}}{\partial \tau}>0 .
$$

For the continuing engineer, because the welfare gain from the higher rates of return dominates the loss from the lower new worth, welfare increases, $\frac{\partial V^{E E}}{\partial \tau}>$ 0 . For the retiring engineer, the loss from lower net worth dominates the gain from the higher rates of return when she becomes an engineer in the future, and thus welfare decreases, $\frac{\partial V^{E S}}{\partial \tau}<0$. For those who were the savers in the previous period, there is no capital loss and only gains from the higher rates of return, and welfare increases, $\frac{\partial V^{S E}}{\partial \tau}, \frac{\partial V^{S S}}{\partial \tau}>0$.

\subsection{Alternative Measures of Investment, Asset Value and Foreign Debt}

In the baseline model, we assume that plant owners pay a fixed cost, or, we might instead suppose, rent buildings from foreign landlords for production. While this assumption simplifies the presentation, the resulting measures of investment, asset value, and foreign debt, may look counterintuitive. For example, when a decline in interest rate leads to lower growth, it decreases aggregate investment and asset value. And foreign debt are typically negative.

In Section 7, we assume instead that engineers and plant owners buy buildings from foreign builders. This appendix explains the alternative measurement in more detail.

When an agent has $h_{t}$ units of tools, $k_{t}$ units of plant and building, and $d_{t}^{*}$ units of foreign debt at the beginning of period, her budget constraint is

$$
c_{t}+\left(x+q_{t}-b_{t}-q_{t}\right) i_{t}+\frac{d_{t+1}}{R_{t}}=w_{t} h_{t}+\left[a-w_{t}+\lambda\left(b_{t}+q_{t}\right)\right] k_{t}-d_{t}^{*} .
$$

$a-w_{t}$ is a plant owner's flow return; $\lambda\left(b_{t}+q_{t}\right)$ is the capital value of plant and building after use. Using $h_{t+1}=\lambda h_{t}+i_{t}$ for an engineer, the budget constraint is

$$
c_{t}+\left(x-b_{t}\right) h_{t+1}+\frac{d_{t+1}}{R_{t}}=\left[w_{t}+\lambda\left(x-b_{t}\right)\right] h_{t}+\left[a-w_{t}+\lambda\left(b_{t}+q_{t}\right)\right] k_{t}-d_{t}^{*} .
$$


In the pure equilibrium with no stopping, the aggregate number of tools and plant are equal:

$$
H_{t}=K_{t}
$$

Thus the aggregate net worth of engineers and savers are

$$
\begin{gathered}
N_{t}^{E}=\pi^{E}\left[w_{t}+\lambda\left(x-b_{t}\right)\right] K_{t}+\pi^{S}\left\{\left[a-w_{t}+\lambda\left(b_{t}+q_{t}\right)\right] K_{t}-D_{t}^{*}\right\}, \\
N_{t}^{S}=\left(1-\pi^{E}\right)\left[w_{t}+\lambda\left(x-b_{t}\right)\right] K_{t}+\left(1-\pi^{S}\right)\left\{\left[a-w_{t}+\lambda\left(b_{t}+q_{t}\right)\right] K_{t}-D_{t}^{*}\right\} .
\end{gathered}
$$

Total net worth is

$$
N_{t}=N_{t}^{E}+N_{t}^{S}=\left[a+\lambda\left(x+q_{t}\right)\right] K_{t}-D_{t}^{*} .
$$

Aggregate consumption is

$$
\begin{aligned}
C_{t} & =(1-\beta) N_{t} \\
& =(1-\beta)\left\{\left[a+\lambda\left(x+q_{t}\right)\right] K_{t}-D_{t}^{*}\right\} .
\end{aligned}
$$

The downpayment for aggregate plant and building is financed by the net worth of engineers (after consumption):

$$
\left(x+q_{t}-b_{t}-q_{t}\right) K_{t+1}=\beta N_{t}^{E},
$$

or

$$
\left(x-b_{t}\right) K_{t+1}=\beta \pi^{E}\left[w_{t}+\lambda\left(x-b_{t}\right)\right] K_{t}+\beta \pi^{S}\left\{\left[a-w_{t}+\lambda\left(b_{t}+q_{t}\right)\right] K_{t}-D_{t}^{*}\right\} .
$$

Foreign debt evolves with current account as

$$
\begin{aligned}
\frac{D_{t+1}^{*}}{R_{t}} & =D_{t}^{*}+C_{t}+\left(x+q_{t}\right)\left(K_{t+1}-\lambda K_{t}\right)-a K_{t} \\
& =\beta D_{t}^{*}-\beta\left[a+\lambda\left(x+q_{t}\right)\right] K_{t}+\left(x+q_{t}\right) K_{t+1}
\end{aligned}
$$

The dynamics of aggregate plant and building and foreign debt are described by $(77,78)$.

Note that foreign debt in this setting is a lot greater than that in the main setting where engineers rent land. Denote the foreign debt in the baseline setting as $D_{t}^{o *}$. The net worth of the baseline setting is

$$
N_{t}=N_{t}^{E}+N_{t}^{S}=(a+\lambda x-f) K_{t}-D_{t}^{o *} .
$$


Net foreign debt in the alternative setting is given by (76). Without any unexpected shock to the interest rate, net worth is the same in the two settings. This implies that

$$
D_{t}^{*}=\left(f+\lambda q_{t}\right) K_{t}+D_{t}^{o *}
$$

Although buying or renting buildings does not affect investment given the initial net worth of the economy, $N_{t}^{E}$ and $N_{t}^{S}$, it may affect how net worth responds to an unexpected shock to the interest rate. When engineers buy buildings, their current building holdings were purchased at past prices which depended on past interest rates. If foreign debt is not indexed to interest rate changes, an unexpected decrease in interest rate increases the net worth of the economy much more when plant owners buy buildings, as we see from equations $(79,76)$.

\subsection{Calibration strategy}

We choose the following parameter values, $\theta, \eta, \lambda, \beta, \pi^{E}$ and $\pi^{S}$. We normalize the productivity of plant productivity $a$ to be 1 .

We solve for $f$ such that the economy is at the boundary between Region $P$ and Region $M$ at $R=1.015$. We design an algorithm to solve for the infinum of the set of $f$ for which a plant owner stops in a finite number of periods.

Suppose the plant owner stops in $T$ period at a particular value of $f$. Then $S^{t}(1 ; f, w, R)$ as a function of $t$ reaches its peak at $T$. Define a sequence of $f_{t}$ such that at $f=f_{t}$, for $z^{*}=1$ :

$$
S^{t+1}\left(1 ; f_{t}, w, R\right)=S^{t}\left(1 ; f_{t}, w, R\right) .
$$

Intuitively, $f_{t}$ tracks the movement in the peak as we vary $f$. If $f=f_{t}$, the peak is either $t$ or $t+1$. As $t$ goes to infinity, the peak shifts to infinity. Because

$$
S^{t+1}(1 ; a, w, r)=U^{t+1}(1 ; R)-\left(\frac{1}{R}+\frac{\lambda}{R^{2}}+\ldots+\frac{\lambda^{t}}{R^{t+1}}\right) f
$$

and

$$
S^{t}(1 ; a, w, r)=U^{t}(1 ; R)-\left(\frac{1}{R}+\frac{\lambda}{R^{2}}+\ldots+\frac{\lambda^{t-1}}{R^{t}}\right) f
$$


we have

$$
f_{t}=\frac{R^{t+1}}{\lambda^{t}}\left[U^{t+1}(1 ; R)-U^{t}(1 ; R)\right] .
$$

The calibrated value of $f$ is equal to $\inf _{t=1,2, \ldots} f_{t}$, which we approximate by $\min _{t=1,2, \ldots, T} f_{t}$ with $T$ large enough. For any value of $f$ strictly above $\inf _{t=1,2, \ldots} f_{t}$, there must exist a finite optimal stopping time. For any value of $f$ strictly below $\inf _{t=1,2, \ldots} f_{t}$, there cannot exist a finite stopping time.

After we calibrate the value of $f$, we solve for $x$ to target a growth rate of $0.5 \%$ at gross interest rate $R=1.015$.

$$
x=\frac{a-f-w}{R-\lambda}+\frac{\beta \Pi}{G-\beta \lambda \Pi} w,
$$

where $w=\frac{\lambda \eta}{R-\theta \lambda} a$ and

$$
\Pi=\pi^{E}+\pi^{S} \frac{\beta R\left(1-\pi^{E}\right)}{G-\beta R\left(1-\pi^{S}\right)} .
$$

